\title{
CONTRIBUIÇÕES PARA A ANÁLISE DA DINÂMICA CLIMATOLÓGICA NO MUNICÍPIO DE SÃO GONÇALO/RJ: 2008 - 2018
}

\author{
CONTRIBUTIONS TO THE DYNAMIC CLIMATOLOGICAL ANALYSIS FOR THE MUNICIPALITY \\ OF SÃO GONÇALO/RJ: 2008 - 2018
}

\author{
${ }^{\text {A }}$ Universidade do Estado do Rio de Janeiro (UERJ), Rio de Janeiro, RJ Brasil

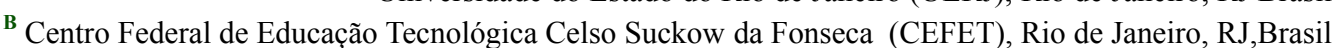 \\ ${ }^{\mathrm{C}}$ Universidade Federal de Viçosa (UFV), Viçosa, MG, Brasil
}

\author{
Recebido em: 03/06/2021 | 11/06/2021～DOI: 10.12957/tamoios.2021.58214 \\ Correspondência para: Vanessa Cristina Matos Pereira (vanessamatos.meteorologia@gmail.com)
}

\begin{abstract}
Resumo
O estudo do comportamento das variáveis meteorológicas de uma localidade é de suma importância para conhecer o seu clima. O objetivo deste trabalho é analisar as variáveis meteorológicas, no período de 2008 a 2018 , monitoradas na Estação Climatológica Experimental Urbana da Universidade do Estado do Rio de Janeiro/Faculdade de Formação de Professores (UERJ/FFP), localizada no município de São Gonçalo-RJ. A metodologia consistiu em utilizar os dados compostos pela série histórica de pluviosidade, insolação, pressão atmosférica, nebulosidade, temperaturas do ar e do solo, umidade relativa, evaporação e vento através da comparação da estação meteorológica denominada Rio de Janeiro do Instituto Nacional de Meteorologia (INMET) para efeito de comparação dos dados. Os resultados demonstraram que existe a possibilidade do clima do município de São Gonçalo-RJ ser Aw, de acordo com a classificação de Köppen.
\end{abstract}

Palavras-chave: Clima; São Gonçalo; Variáveis meteorológicas; Estação Climatológica.

\begin{abstract}
Analysis of the climate of a city or region is important to understand the behavior of the meteorological variables as well as other information that can help formulate policies to support the population. This document continues the work regarding climatic characterization of the municipality of São Gonçalo, located in the Rio de Janeiro Metropolitan Region. The method consisted of using data from the Experimental Urban Climatological Station of Rio de Janeiro State University, consisting of historical series on rainfall, insolation, atmospheric pressure cloud cover, air and soil temperature, relative humidity, evaporation and wind, covering the period from 2008 to 2018. These data were compared with data from the National Institute of Meteorology (INMET). The results demonstrated that the climate of São Gonçalo can be classified as Aw on the Köppen scale. However, a longer monitoring period is necessary to better understand the local climate.
\end{abstract}

Keywords: Climate; São Gonçalo; Meteorological variables; Climatological station. 


\section{INTRODUÇÃO}

Estudar as características climáticas de uma localidade proporciona orientações para diversos setores como o agrícola (CARDOSO et al. 2009; EMBRAPA SOLOS, 2013), meio ambiente (COSTA, 2021) e ensino (BERTOLINO, 2018; FIALHO, 2018; ALHO; TORNIO; KEDE, 2019; KEDE; BERTOLINO; BERTOLINO, 2017) entre outros, visto que a dinâmica atmosférica ocasiona inúmeras influências à sociedade. Segundo Mendonça e Souza (2010) a pesquisa do clima é necessária para o desenvolvimento urbano, de modo que as ocorrências de fenômenos atmosféricos não causem prejuízos sociais, econômicos e ambientais e que também possam ser minimizados. Dentro do contexto de áreas urbanas a caracterização climática pode também auxiliar em estudos associados às questões de movimentos de massa (SILVA, 2006; SILVA, 2007; PEREIRA, 2019; BERTOLINO et al., 2012; ROSA, 2013; OLIVEIRA, 2015; BERTOLINO et al., 2016) e inundações (SILVA, 2006; COSTA, 2014; DELAZERI, 2015, RIBEIRO et al. 2018; PEREIRA et al., 2019).

A variação espacial e temporal que caracteriza o clima é resultado de interações de elementos e fatores de uma determinada localidade. Para conhecer o clima de qualquer área é necessário o monitoramento do tempo nas estações climatológicas. $O$ resultado da combinação momentânea de atributos da atmosfera como as temperaturas do ar, velocidade do vento, precipitação, umidade relativa, pressão atmosférica, insolação, dentre outras, caracterizam os diversos tipos de tempo e a sucessão habitual do tempo que podem ser interpretadas como os estados da atmosfera que constitui o clima (TAVARES, 2004). Além disso, a utilização de imagens de satélite disponibilizadas, por exemplo, pelo Instituto Nacional de Pesquisas Espaciais (INPE) e de cartas sinóticas fornecidas pela Diretoria de Hidrografia e Navegação (DHN), corroboram no entendimento da dinâmica climatológica de uma localidade.

Os problemas ambientais-urbanos estão associados a diversas questões e podem trazer problemas de ordem social, física e econômica. Nas últimas décadas vem ocorrendo um avanço acelerado na ocupação das encostas e de inundações, associadas ao empobrecimento da população. Esta intervenção antrópica vem alterando as condições ambientais, o que tem resultado em problemas, tendo como consequências imediatas, perdas de bens materiais e vidas humanas (PINGUELLI ROSA; LACERDA, 1997).

A partir dos estudos desenvolvidos pelo Departamento de Geografia - FFP no município de São Gonçalo busca-se a caracterização climática da localidade com o objetivo de ter a possibilidade de um planejamento, sobretudo ambiental, a partir da observação da variação atmosférica. Intrinsecamente relacionado a isto, observa-se o agravamento de problemas socioambientais, uma vez que estes são gerados pela falta de um melhor gerenciamento ao nível dos municípios (FIALHO et al., 2005; FIALHO; LELIS, 2007), tendo em vista que nem sempre existem instrumentos adequados para tal caracterização. Sendo 
assim, é essencial o estudo do comportamento climatológico para o desenvolvimento urbano e rural em quaisquer localidades.

O objetivo deste trabalho é analisar as variáveis meteorológicas, no período de 2008 a 2018, monitoradas na Estação Climatológica Experimental Urbana da Universidade do Estado do Rio de Janeiro/Faculdade de Formação de Professores (UERJ/FFP), localizada no município de São Gonçalo-RJ.

\section{METODOLOGIA}

\section{Área de Estudo}

São Gonçalo é um município pertencente à região Metropolitana do Rio de Janeiro e está localizado entre as coordenadas $22^{\circ} 49^{\prime} 55,97^{\prime \prime} \mathrm{S}$ e $43^{\circ} 4^{\prime} 25,52^{\prime \prime} \mathrm{W}$, tendo como limites ao norte Itaboraí e Baía de Guanabara, ao sul com Maricá e Niterói, a leste Itaboraí e Maricá e a oeste Baía de Guanabara. Segundo o Instituto Brasileiro de Geografia e Estatística (IBGE, 2018), possui área de $248,160 \mathrm{~km}^{2}$, área urbana arborizada de $34,4 \%$ e $65 \%$ do terreno se localiza em região de baixada (SALGADO et al, 2007). No contexto da Baía de Guanabara, observa-se grande degradação ambiental, estratificação social e um quadro de baixa qualidade de vida (AMADOR, 1997). Na Figura 1 pode-se observar o bairro Patronato, no qual se situa a Estação Climatológica Experimental Urbana da UERJ/FFP.

Figura 1 - Localização do município de São Gonçalo - RJ e do bairro Patronato. 


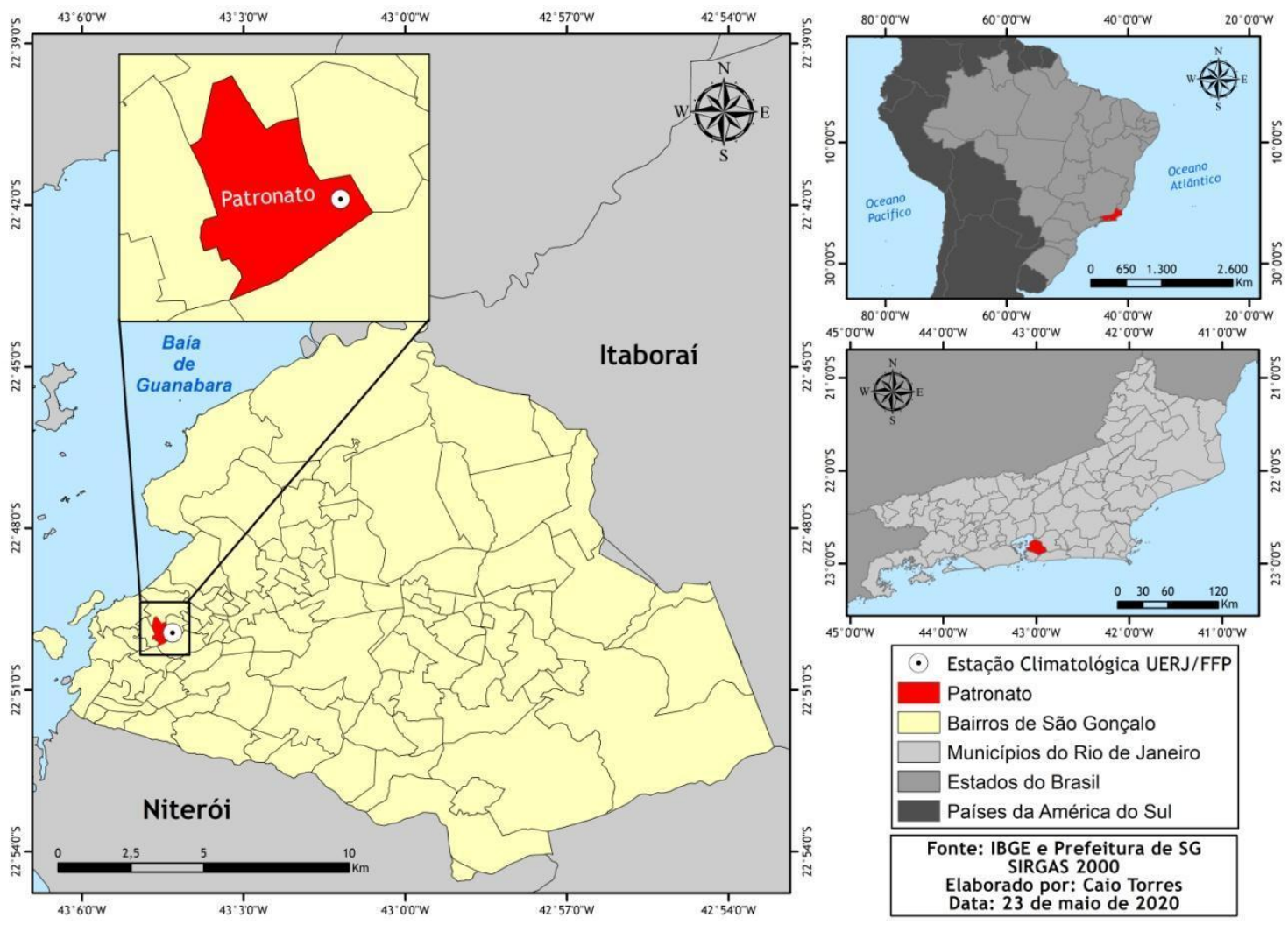

Fonte: IBGE e Prefeitura de São Gonçalo (2019).

O município de São Gonçalo localiza-se em uma faixa de transição climática, onde segundo Borsato (2016) atuam as cinco massas de ar. Porém, a situação latitudinal do município faz com que todas as massas de ar ao atuar no local, distantes das áreas de origem, apresentam-se amplamente modificadas, exceto a Massa Equatorial Continental $(\mathrm{mEc})$ que preserva as características originais em toda a área de atuação. Além dessas massas de ar, atuam na faixa litorânea os Sistemas Frontais, os quais, segundo Vianello e Alves (2012) e Varejão-Silva (2006), consistem em um sistema com uma zona de transição entre massas de ar de características distintas e que geram gradientes de temperatura e de pressão que, de forma bastante simplificada, consistem em uma estreita faixa de ares convergentes que se configura e avança ao norte de uma massa Polar. Como o ar quente dos ares tropicais tem densidade menor, o ar frio da massa Polar avança na forma de uma cunha e eleva o ar tropical que se desestabiliza para as áreas de mais umidade. Essa configuração é mais evidente ao Sul do Trópico de Capricórnio. Ao norte desse limite, essa faixa de intensa nebulosidade perde as características na medida em que o ar polar assimila calor das áreas deslocadas.

Outro fenômeno que gera influência no município é a Zona de Convergência do Atlântico Sul (ZCAS), que consiste em uma faixa de nebulosidade se estendendo desde a região Norte até o Sudeste do Brasil, passando pelo Centro-Oeste, ocasionando um período prolongado de chuvas nessas regiões. Os episódios de ZCAS transportam calor e umidade da Amazônia influenciando fortemente a precipitação nos verões, mas, importantes variações 
ocorrem na intensidade das chuvas e na circulação (CARVALHO; JONES, 2009). Alguns episódios das ZCAS provocam transtornos ao município de São Gonçalo e para os outros municípios da região metropolitana, como inundações e movimentos de massa.

Além disso, a localização de São Gonçalo, inserido dentro da Baía de Guanabara, mais precisamente, na porção leste, possui um regime de ventos com maior predominância de Nordeste (NE) e Leste (L) associado ao Anticiclone Subtropical do Atlântico Sul (ASAS) atuando no outono e inverno quando ocorre um aumento dos ventos NE e L. As alterações nas direções dos ventos ocorrem com a chegada de sistemas frontais ou no verão e na primavera durante a maior influência da circulação da brisa marítima (PIMENTEL et al., 2014; OLIVEIRA JÚNIOR et al., 2013; BRITO et al., 2016).

\section{Estação Climatológica Urbana Experimental}

No presente estudo, são analisados os parâmetros climáticos da Estação Meteorológica da UERJ-FFP, cuja altitude é de $20 \mathrm{~m}$, para o período de 2008 a 2018 (figura 2). Para efetuar as análises, neste intervalo de tempo, foram coletados dados dos equipamentos existentes na Estação Climatológica Experimental Urbana da UERJ/FFP todos os dias às 12 TMG (09 horas local), conforme normas do Instituto Nacional de Meteorologia (INMET).

A intensidade de chuva foi analisada segundo os parâmetros atuais do Sistema Alerta-Rio da Prefeitura da Cidade do Rio de Janeiro (2020), que classifica as chuvas em: insignificante $(<1,0 \mathrm{~mm} / \mathrm{h})$, leve $(1,1$ a $5,0 \mathrm{~mm} / \mathrm{h})$, moderada $(5,1$ a $25 \mathrm{~mm} / \mathrm{h})$, forte $(25,1$ a $50 \mathrm{~mm} / \mathrm{h}$ ) e muito forte $(>50 \mathrm{~mm} / \mathrm{h})$.

Após a coleta, os dados foram organizados em planilha, tiveram aplicação de técnicas estatísticas - no caso específico, a realização de médias de variáveis como temperaturas do ar e do solo, pressão, nebulosidade e vento. Em outros casos, foram considerados seus totais, como insolação, pluviosidade e evaporação. Os dados de precipitação, temperaturas do ar (média, máxima e mínima) e pressão atmosférica foram comparados aos dados da estação denominada Rio de Janeiro (SBRJ), localizada no Aeroporto Santos Dummont, a qual foi selecionada por ser a estação do INMET, que possui as Normais Climatológicas, mais próximas de São Gonçalo-RJ com uma série histórica, desde 1961 a 1990, o que proporciona maior conhecimento climático da região analisada.

Figura 2: Estação Climatológica convencional situada Universidade do Estado do Rio de Janeiro/Faculdade de Formação de Professores: 1) Geotermômetros; 2) Pluviômetro; 3) Abrigo meteorológico; 4) Pluviógrafo; 5) Anemômetro; 6) Tanque de evaporação; 7)

$$
\text { Heliógrafo. }
$$




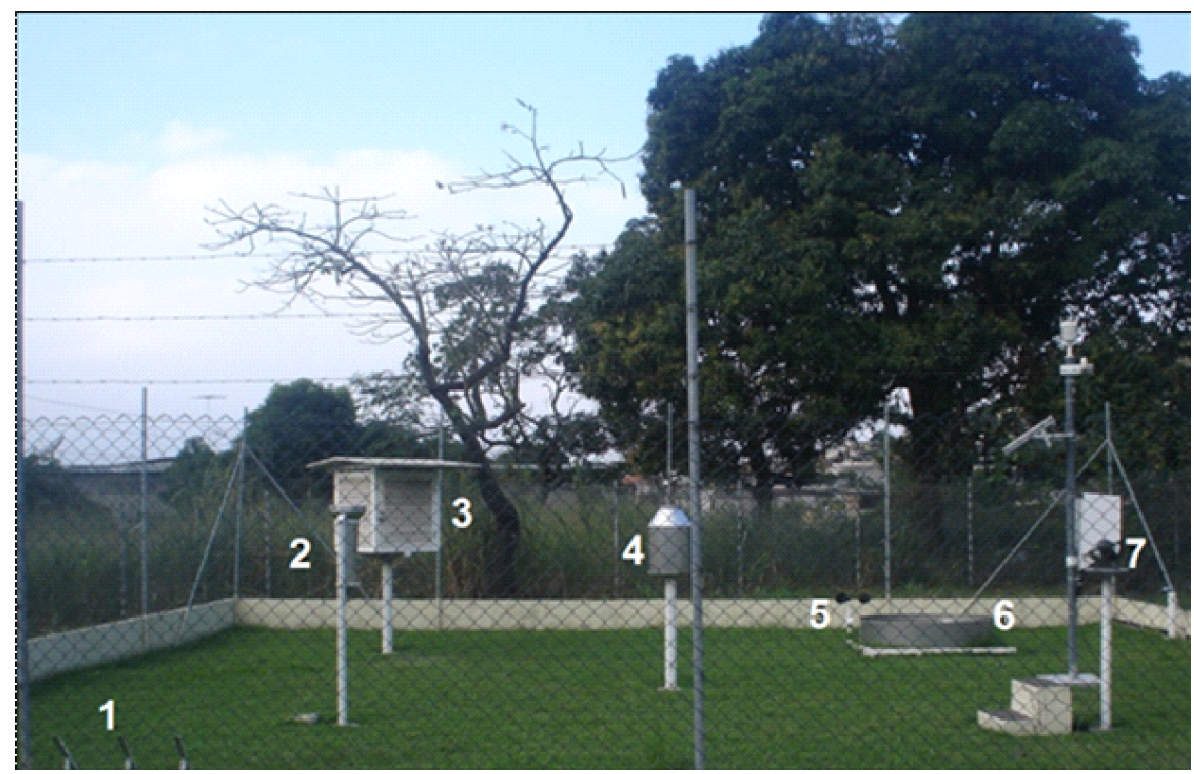

Fonte: Laboratório de Geociências da UERJ/FFP.

Por fim, foi calculado o índice xerotérmico para a representação dos períodos secos e úmidos, a fim de conhecer melhor a dinâmica climática do município em questão e confirmar a tendência climática Aw de Köppen (AYOADE, 1996). A metodologia utilizada foi a de Bognouls e Gaussen (1962), que considera que o período seco se estabelece quando a pluviosidade mensal $(\mathrm{P})$ expressa em $\mathrm{mm}$ é inferior ao dobro da temperatura média mensal (T), expressa em ${ }^{\circ} \mathrm{C}$. A temperatura do ar foi definida como o dobro da pluviosidade, conforme proposta de Bognouls e Gaussen (1962), onde os meses secos e úmidos foram definidos a partir das Equações 1 (mês úmido) e 2 (mês seco) abaixo descritas.

$$
\begin{aligned}
& \mathrm{P} \geq 2 \mathrm{~T}=\text { Mês úmido (1) } \\
& \mathrm{P}<2 \mathrm{~T}=\text { Mês seco (2) }
\end{aligned}
$$

Foram utilizados, dentre outros, os dados de temperaturas médias e absolutas, acumulados mensais e anuais de precipitação, umidade relativa média mensal, taxas de evaporação mensal, dados de temperatura do solo em $11 \mathrm{~cm}, 21 \mathrm{~cm}$ e $31 \mathrm{~cm}$ de profundidade, velocidade média do vento, insolação e nebulosidade. Além da análise dos dados à luz da atuação do El Niño, o qual proporcionou modulação nas variáveis meteorológicas através de suas edições dentro da série histórica destacada para o trabalho em questão, como nos anos de 2005/2006, 2009/2010, 2014/2016, 2018/2019, conforme National Centers for Environmental Information-NOAA (2020).

Por fim, para entender o comportamento das dinâmicas climáticas atuais, torna-se crucial a comparação de tais informações com dados de estações próximas que possuam séries históricas abrangendo períodos maiores, de modo a comparar o comportamento dessas dinâmicas no período anterior com o período atual, visando confirmar a tendência de Aw, conforme a classificação de Köppen (AYOADE, 1996), e proporcionar clareza na 
interpretação de tais dados, para a correta compreensão, como trabalhos que foram produzidos no Laboratório de Geociências (LabGeo), tais como Bertolino et al (2007), Silva et al (2019), Pereira et al (2019), Tórnio, (2019), entre outros.

\section{RESULTADOS}

Ao observar os dados da série de análise, com base na proposta por Bognouls e Gaussen (1962), constatou-se que os períodos secos correspondem aos meses de maio a outubro, os quais possuem 184 dias. E os períodos úmidos, que abrangem os meses de novembro a abril, e que possuem 181 dias. Constata-se que o município de São Gonçalo para o período de 2008 a 2018 se caracteriza por apresentar um verão quente e chuvoso, compreendido entre dezembro e março, e inverno seco (figura 3). Esse comportamento permite enquadrar São Gonçalo em uma faixa de transição de atuação de sistemas tropicais e extratropicais, permitindo identificar uma sazonalidade entre maio e setembro (meses secos), o que coaduna com uma classificação de Walter (1986). Isso identifica essa estação com perfil climático Tropical de Floresta estacional densa semidecídua, ou seja, um clima marcado por uma variação sazonal definida pela distribuição da pluviosidade. Essas características são corroboradas pela produção de pesquisas hidroerosivas que são realizadas na UERJ/FFP, tais como Santos et al. (2019), Pereira et al. (2019), Silva et al. (2019), Tórnio (2019), Tórnio e Kede (2019), entre outros.

Figura 3 - Gráfico ombrotérmico do município de São Gonçalo - RJ (2008-2018).

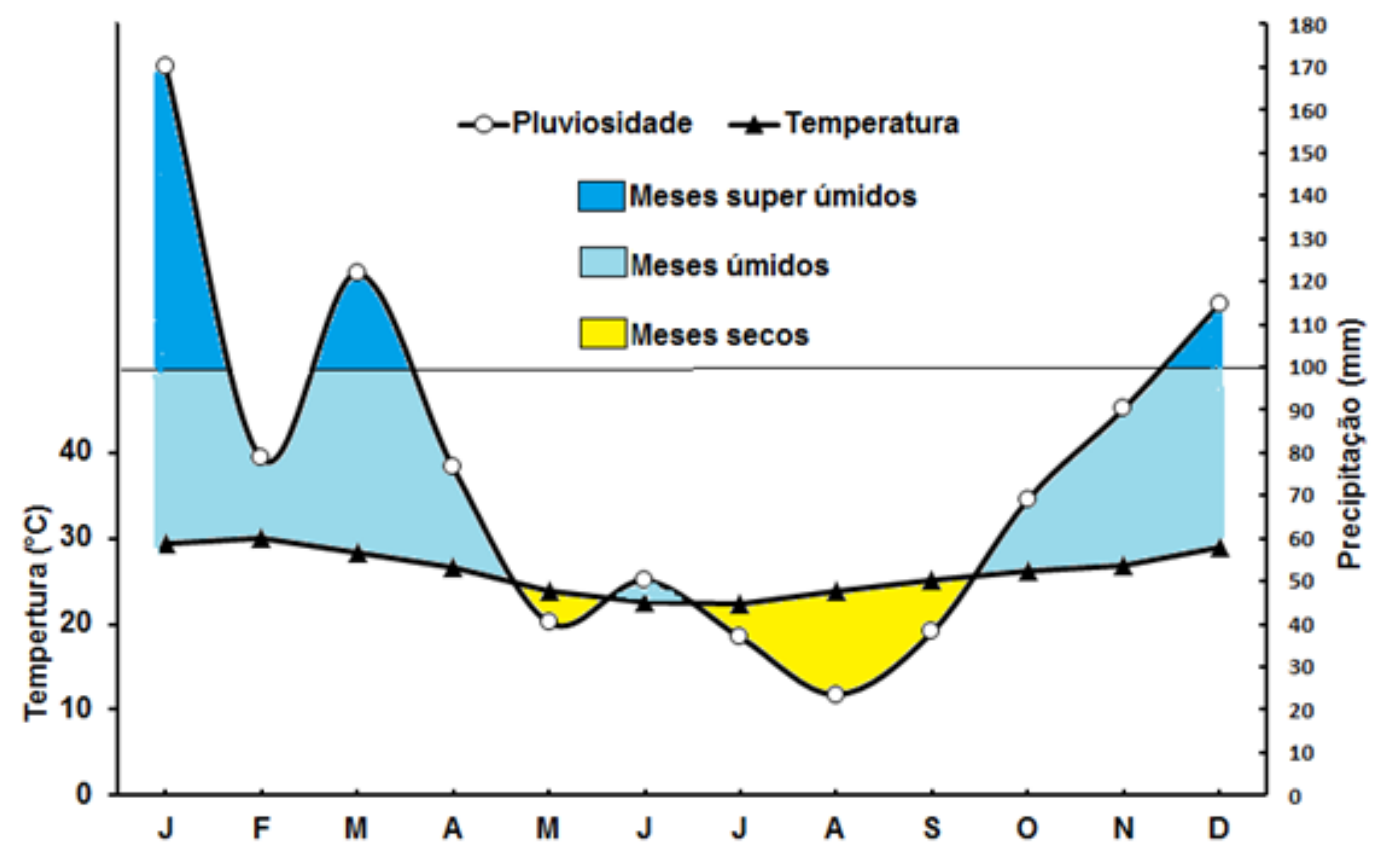


Fonte: Laboratório de Geociências da UERJ/FFP (Estação Meteorológica UERJ-FFP).

\section{Temperaturas}

A tabela 1 apresenta as temperaturas máximas e mínimas ao longo da série histórica de 2008-2018. É possível identificar, através dos dados apresentados, que as temperaturas máximas, no geral, estão mais altas até o ano de 2014. A temperatura máxima mais baixa $\left(39,6^{\circ} \mathrm{C}\right)$ registrada em 2009 corresponde a $0,7^{\circ} \mathrm{C}$ acima da temperatura máxima absoluta registrada na estação $\operatorname{SBRJ}$ do $\operatorname{INMET}\left(38,9^{\circ} \mathrm{C}\right)$. A temperatura máxima mais elevada da série histórica ocorreu no ano de 2014 , quando foram registrados $44,2^{\circ} \mathrm{C}$, sendo $5,1^{\circ} \mathrm{C}$ mais elevados que a média anual apresentada nas normais climatológicas. $\mathrm{O}$ ano de 2014, segundo Pegorim (2014), foi considerado um ano atípico devido à forte atuação da Alta Subtropical do Atlântico Sul (ASAS) ao longo do verão. Somando a esta anomalia, Chade (2015) informa que a Organização Meteorológica Mundial (OMM) verificou dados, os quais foram reafirmados pela National Aeronauticsand Space Administration (NASA) por indicarem que até então 2014 havia sido "o ano mais quente jamais identificado", seguido pelos anos anteriores que também apresentaram temperaturas elevadas, como 2013 com $44,0^{\circ} \mathrm{C}, 2012$ com $43,0^{\circ} \mathrm{C}$, entre outros.

As temperaturas máximas e mínimas em períodos secos correspondem aos meses de maio a outubro e os períodos úmidos abrangem os meses de novembro a abril. Conforme os dados observados, a temperatura mínima atingiu seu mínimo absoluto durante o período úmido, com registros que alcançaram $13,0^{\circ} \mathrm{C}$ no mês de fevereiro de 2012 e em janeiro de 2016.

Tabela 1 - Temperaturas máximas e mínimas absolutas registradas na Estação Climatológica UERJ/FFP/SG.

\begin{tabular}{c|c|c|c|c|c|c|c|c}
\hline \multicolumn{6}{c}{ Temperaturas máximas e mínimas nos períodos secos e úmidos ( ${ }^{\circ}$ C) } \\
\hline \multirow{2}{*}{ Período } & Máx & $\begin{array}{c}\text { Mês de } \\
\text { ocorrência }\end{array}$ & Mín & $\begin{array}{c}\text { Mês de } \\
\text { ocorrência }\end{array}$ & $\begin{array}{c}\text { Má } \\
\mathbf{x}\end{array}$ & Mín & $\begin{array}{c}\text { Má } \\
\mathbf{x}\end{array}$ & $\begin{array}{c}\text { Mí } \\
\mathbf{n}\end{array}$ \\
\hline $\mathbf{2 0 0 8}$ & 40,0 & Fevereiro & 14,0 & Julho & 37,2 & 14,0 & 40,0 & $\begin{array}{c}18, \\
2\end{array}$ \\
\hline $\mathbf{2 0 0 9}$ & 39,6 & Março & 16,0 & Março & 37,6 & $*$ & 39,6 & $\begin{array}{c}16, \\
0\end{array}$ \\
\hline $\mathbf{2 0 1 0}$ & 40,2 & Abril & 13,8 & Outubro & 38,0 & 13,8 & 40,2 & $\begin{array}{c}17, \\
2\end{array}$ \\
\hline $\mathbf{2 0 1 1}$ & 41,2 & Janeiro & 14,2 & Julho & 38,2 & 14,2 & 41,2 & $\begin{array}{c}15, \\
8\end{array}$ \\
\hline
\end{tabular}




\begin{tabular}{c|c|c|c|c|c|c|c|c}
\hline $\mathbf{2 0 1 2}$ & 43,0 & Dezembro & 13,0 & Fevereiro & 41,8 & 15,0 & 43,0 & $\begin{array}{c}13, \\
0\end{array}$ \\
\hline $\mathbf{2 0 1 3}$ & 44,0 & Fevereiro & 16,0 & Julho & 42,2 & 16,0 & 44,0 & $\begin{array}{c}13, \\
2\end{array}$ \\
\hline $\mathbf{2 0 1 4}$ & 44,2 & Março & 12,6 & Março & 41,2 & 14,0 & 44,2 & $\begin{array}{c}12, \\
6\end{array}$ \\
\hline $\mathbf{2 0 1 5}$ & 42,4 & Março & 13,8 & Abril & 42,2 & 14,6 & 42,4 & $\begin{array}{c}13, \\
8\end{array}$ \\
\hline $\mathbf{2 0 1 6}$ & 42,2 & Outubro & 15,0 & Outubro & 42,2 & 15,0 & 41,8 & $\begin{array}{c}13, \\
0\end{array}$ \\
\hline $\mathbf{2 0 1 7}$ & 40,2 & Janeiro & 14,0 & Abril & 39,0 & 18,0 & 40,2 & $\begin{array}{c}14, \\
0\end{array}$ \\
\hline $\mathbf{2 0 1 8}$ & 40,4 & Novembro & 20,4 & Julho & 37,7 & 20,4 & 40,4 & $\begin{array}{c}24, \\
8\end{array}$ \\
\hline
\end{tabular}

Legenda: *Problemas no monitoramento.

Fonte: Laboratório de Geociências da UERJ/FFP.

A temperatura máxima também atingiu seu máximo absoluto durante o período úmido, com registros de até $44,2^{\circ} \mathrm{C}$ que ocorreu em março de 2014 , apresentando um aumento de $7,0^{\circ} \mathrm{C}$ quando comparada à temperatura máxima absoluta $\left(37,2^{\circ} \mathrm{C}\right)$ registrada nas Normais Climatológicas da estação SBRJ, do INMET, em setembro/1981. No entanto, as temperaturas médias registradas no período úmido de toda a série histórica ficaram entre $26,7^{\circ} \mathrm{C}$ (a qual foi a menor média), que foi registrada em 2008, e a maior temperatura média do mesmo período ocorreu em 2014 , com $29,6^{\circ} \mathrm{C}$. Quanto ao período seco do intervalo estudado, a temperatura média variou entre $22,9^{\circ} \mathrm{C}\left(\mathrm{em} \mathrm{2011)} \mathrm{e} 25,3^{\circ} \mathrm{C}(\mathrm{em} \mathrm{2015)}\right.$.

É possível refletir sobre a associação da diferença entre a temperatura máxima e mínima absoluta registrada pela estação SBRJ do INMET, provavelmente, como aumento da urbanização no município de São Gonçalo ao longo dos anos. Entretanto, para confirmar essa possibilidade da causa do aumento térmico é necessário analisar os diferentes níveis de urbanização com uma série histórica maior. Em estudo verificado por Corrêa (2005), quando investigou o campo térmico no distrito de Neves, bem na região metropolitana do Rio de Janeiro (BRANDÃO, 1992), e na cidade do Rio de Janeiro (BRANDÃO, 1996 e 1997; FIALHO, 2010), constataram-se a relação entre o tipo de uso da terra e o incremento da temperatura do ar. A temperatura mínima no mesmo período úmido foi registrada em fevereiro do ano de 2014 , com $12,6^{\circ} \mathrm{C}$ e $1,1^{\circ} \mathrm{C}$ acima das Normais Climatológicas, cuja temperatura mínima absoluta ocorreu em maio de 1990.

\section{Precipitação}

Observando a tabela 2, as temperaturas absolutas e o acumulado pluviométrico, identificou-se que o maior volume anual de chuva ocorreu em 2010 com $1.386 \mathrm{~mm}$. A maior 
parte desse acumulado ocorreu no período úmido, com total de $1.128 \mathrm{~mm}$ em 2010 . O mês que registrou o maior acumulado de chuva do verão de 2010 foi março com $296 \mathrm{~mm}$, seguido por dezembro com $193 \mathrm{~mm}$ e janeiro com $187 \mathrm{~mm}$. Observa-se que, apesar de 2010 ter sido o ano mais chuvoso de toda a série histórica, a quantidade de dias com precipitação no período úmido foi maior em 2008 com 100 dias.

Tabela 2 - Acumulados anuais e dias chuvosos registrados na Estação UERJ/FFP/SG.

\begin{tabular}{c|c|c|c|c|c|c}
\hline \multirow{2}{*}{ Anos } & \multicolumn{3}{|c|}{ Total pluviométrico anual (mm) } & \multicolumn{3}{c}{ Dias de chuva } \\
\cline { 2 - 7 } & \multicolumn{3}{|c|}{ Períodos } & \multicolumn{3}{c}{ Períodos } \\
\cline { 2 - 7 } & Seco & Úmido & Acumulados & Seco & Úmido & $\begin{array}{c}\text { Tot } \\
\text { al }\end{array}$ \\
\hline 2008 & 181 & 986 & 1.167 & 28 & 100 & 128 \\
\hline 2009 & 410 & 786 & 1.197 & 59 & 88 & 147 \\
\hline 2010 & 258 & 1.128 & 1.386 & 59 & 83 & 142 \\
\hline 2011 & 649 & 311 & 961 & 51 & 74 & 125 \\
\hline 2012 & 327 & 511 & 839 & 43 & 64 & 107 \\
\hline 2013 & 319 & 799 & 1.119 & 53 & 78 & 131 \\
\hline 2014 & 194 & 349 & 543 & 32 & 37 & 69 \\
\hline 2015 & 206 & 679 & 885 & 43 & 67 & 110 \\
\hline 2016 & 167 & 596 & $763^{*}$ & 20 & 45 & 65 \\
\hline 2017 & 189 & 299 & $489^{*}$ & 35 & 42 & 77 \\
\hline 2018 & 245 & 505 & 742 & 65 & 51 & 116 \\
\hline
\end{tabular}

Legenda:*Problemas no monitoramento.

Fonte: Laboratório de Geociências da UERJ/FFP.

O período de chuvas intensas no verão, por sua vez, coloca em evidência, problemas ambientais quando a associação das chuvas intensas associadas ao tecido urbano com pouca estrutura urbana (GONÇALVES, 2012) incapaz de absorver ou escoar os totais pluviais intensos, ocasionam os fenômenos das enchentes em São Gonçalo-RJ (FIALHO; BRANDÃO, 1995; BRANDÃO 2001; FIALHO et al., 2005; SOUZA et al., 2005 e PEREIRA, 2009) e movimentos de massa (MERAT et al., 2009; BERTOLINO et al., 2012; BERTOLINO et al., 2015; ROSA et al., 2018).

No período seco, os anos que registraram menores acumulados foram 2016, 2008 e 2017 com, respectivamente, $167 \mathrm{~mm}, 181 \mathrm{~mm}$ e $189 \mathrm{~mm}$. Esse comportamento pode ser justificado pela atuação da ASAS no litoral do Sudeste, contribuindo para a redução dos acumulados pluviométricos (TÓRNIO, 2019).

Nos anos de 2010, 2008 e 2009 foram os anos que registraram os maiores acumulados de chuva em seus períodos úmidos com, respectivamente, $1.128 \mathrm{~mm}, 986 \mathrm{~mm}$ e $786 \mathrm{~mm}$. Esse comportamento pode ser justificado pela atuação de sistemas tais como centros de baixa pressão que atuavam em diversas áreas do Brasil, incluindo o litoral fluminense, contribuindo 
para a formação de nebulosidade e elevando o acumulado de chuva. Além da atuação de cavados, ZCAS e sistemas frontais associados a ciclones, os quais ocasionaram instabilidade, deixando os acumulados pluviométricos acima da média. A Tabela 3 mostra os dados referentes à frequência de eventos de chuva em cada ano da série retratada no presente estudo.

Tabela 3 - Totais de eventos de chuva na Estação UERJ/FFP/SG.

\begin{tabular}{c|c|c|c|c|c|c|c|c|c|c|c}
\hline $\begin{array}{c}\text { Frequência } \\
\text { de chuva }\end{array}$ & $\begin{array}{c}\mathbf{2 0 0} \\
\mathbf{8}\end{array}$ & $\begin{array}{c}\mathbf{2 0 0} \\
\mathbf{9}\end{array}$ & $\begin{array}{c}\mathbf{2 0 1} \\
\mathbf{0}\end{array}$ & $\mathbf{2 0 1 1}$ & $\begin{array}{c}\mathbf{2 0 1} \\
\mathbf{2}\end{array}$ & $\begin{array}{c}\mathbf{2 0 1} \\
\mathbf{3}\end{array}$ & $\begin{array}{c}\mathbf{2 0 1} \\
\mathbf{4}\end{array}$ & $\begin{array}{c}\mathbf{2 0 1} \\
\mathbf{5}\end{array}$ & $\begin{array}{c}\mathbf{2 0 1} \\
\mathbf{6}\end{array}$ & $\begin{array}{c}\mathbf{2 0 1} \\
\mathbf{7}\end{array}$ & $\mathbf{2 0 1 8}$ \\
\hline $\mathbf{0 - 1 0} \mathbf{~ m m}$ & 329 & 307 & 344 & 364 & 228 & 288 & 100 & 216 & 147 & 150 & $\begin{array}{c}26 \\
0\end{array}$ \\
$\mathbf{1 0 - 2 0} \mathbf{~ m m}$ & 15 & 18 & 16 & 11 & 23 & 25 & 12 & 14 & 0 & 9 & 10 \\
$\mathbf{2 0 - 3 0} \mathbf{~ m m}$ & 3 & 6 & 7 & 3 & 0 & 4 & 3 & 4 & 5 & 2 & 2 \\
$\mathbf{3 0 - 4 0} \mathbf{~ m m}$ & 4 & 1 & 2 & 4 & 2 & 1 & 0 & 4 & 3 & 1 & 4 \\
$\mathbf{4 0 - 5 0} \mathbf{~ m m}$ & 1 & 3 & 1 & 0 & 1 & 1 & 1 & 0 & 0 & 0 & 0 \\
$\mathbf{7 5 0} \mathbf{~ m m}$ & 2 & 1 & 5 & 0 & 0 & 1 & 0 & 1 & 3 & 0 & 1 \\
\hline Total & 354 & 336 & 375 & 382 & 254 & 320 & 116 & 239 & 158 & 162 & 277 \\
\hline
\end{tabular}

Fonte: Laboratório de Geociências da UERJ/FFP.

Os eventos foram subdivididos em quantidade, variando de 0-10 $\mathrm{mm}, 10-20 \mathrm{~mm}$, 20-30 mm, 30-40 mm, 40-50 mm e $>50 \mathrm{~mm}$. Em 2011 foi registrada a maior quantidade de eventos, totalizando 382 e o ano de 2010 foi o único a apresentar um total de 5 eventos maiores que $50 \mathrm{~mm}$. Essa quantidade total de eventos e, principalmente, os maiores que 50 $\mathrm{mm}$, cabem em estudos posteriores que podem ser analisados intentando uma relação entre estes eventos e a atuação do fenômeno El Niño que esteve atuando na localidade. E o ano que apresentou a menor quantidade de eventos chuvosos foi 2014, com 116 eventos. Vale observar que neste ano não foi registrada atuação dos fenômenos El Niño ou La Niña (VENDRAMINI, 2014) e que a redução da precipitação se deu devido à atuação atípica da ASAS.

A figura 4 apresenta uma comparação entre os dados acumulados mensais de chuva na Estação Climatológica Experimental Urbana de São Gonçalo-RJ com os dados das normais climatológicas da Estação SBRJ. Observa-se nos meses de janeiro e março uma diferença positiva dos dados de São Gonçalo-RJ, pois enquanto os dados das normais climatológicas apresentaram 114,1 mm em janeiro, a estação climatológica de São Gonçalo-RJ apresentou 170,8 mm no mesmo mês. Em abril, a precipitação registrada na estação SBRJ foi de 137,4 mm enquanto na de São Gonçalo-RJ foi de $76,6 \mathrm{~mm}$, ou seja, uma redução de $60,8 \mathrm{~mm}$, que se apresenta mais expressiva do que nos meses seguintes, pois no mês de junho, a diferença 
entre a estação SBRJ (80,4 mm) e a de São Gonçalo-RJ (53,2 mm) foi de 27,2 mm. Em julho foram registrados $56,4 \mathrm{~mm}$ na estação SBRJ, enquanto a precipitação em São Gonçalo-RJ neste mesmo mês foi de 36,9 mm, mostrando uma redução de 19,5 mm. Em agosto, foram registrados 50,5 mm na estação SBRJ enquanto na de São Gonçalo-RJ 23,6 mm, apresentando redução de $26,9 \mathrm{~mm}$. Por fim, o mês de setembro foi o segundo mais discrepante em todo o período seco, com 48,2 $\mathrm{mm}$, visto que a estação SBRJ apresentou $87,1 \mathrm{~mm}$ e a de São Gonçalo-RJ, 38,2 mm.

Nos demais meses, no geral, as normais apresentaram dados mais elevados, principalmente em dezembro quando registraram $169 \mathrm{~mm}$. Enquanto a estação de São Gonçalo-RJ registrou apenas $114,7 \mathrm{~mm}$. Essa discrepância dos dados pode ser justificada por razões de localização, pois o município de São Gonçalo-RJ está em região de fundo de baía, segundo Bertolino et al (2012). Além do mais a presença de maciços costeiros nas proximidades, podem causar o efeito de sombra de chuva, ocasionando uma diminuição e homogeneização da precipitação em toda a região.

Figura 4 - Comparação entre os totais pluviométricos anuais na UERJ/FFP/SG e nas Normais Climatológicas Estação SBRJ.

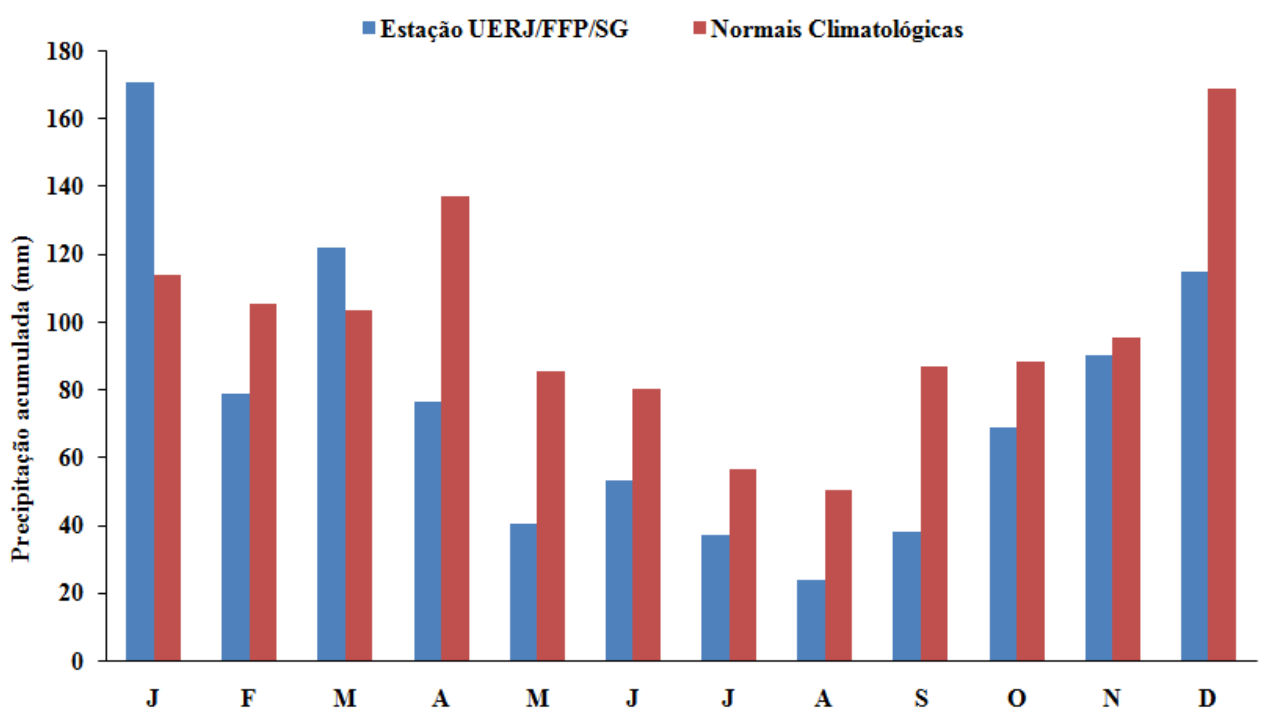

Fonte: Laboratório de Geociências da UERJ/FFP.

\section{Relação entre Temperatura e Precipitação e atuação do El Niño}

A partir da figura 5 identificou-se a relação entre a temperatura média anual e os totais acumulados de precipitação nos mesmos anos. De acordo com as informações apresentadas, os anos de 2014, 2015 e 2016 se mostraram mais quentes, registrando temperaturas médias de $27,0^{\circ} \mathrm{C}, 27,2^{\circ} \mathrm{C}$ e $27,3^{\circ} \mathrm{C}$, respectivamente. Tais temperaturas foram as maiores médias 
registradas em todo o decênio. Esse comportamento sugere que pode estar associado ao fenômeno El Niño que atuou nos anos em questão, aumentando a temperatura média na Região Sudeste (PEREIRA et al., 2019).

Figura 5 - Variação termo-pluviométrica da estação UERJ/FFP/SG (2008-2018).

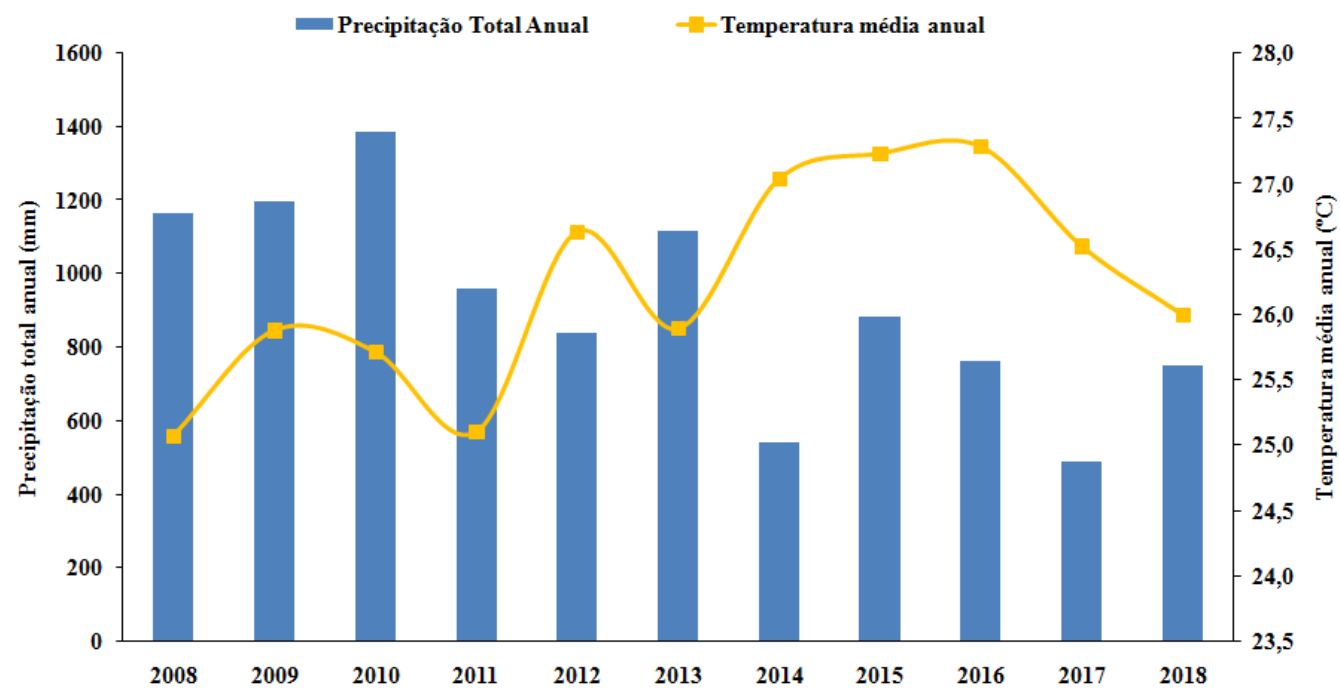

Fonte: Laboratório de Geociências da UERJ/FFP.

Em contrapartida, o El Niño proporciona o aumento indireto do acumulado de chuva na Região Sudeste, porém nos anos de 2015 e 2016 a ASAS esteve atuando de forma atípica, desfavorecendo a formação de nebulosidade devido ao seu movimento de ar subsidente, deixando os acumulados em 2015 com 885,7 mm e 2016 com apenas 763,0 mm (KEDE; BERTOLINO; BERTOLINO, 2017). Essa subsidência de ar explica a diminuição do acumulado anual de chuva quando comparado aos outros anos que sofreram influências do fenômeno El Niño como, por exemplo, o ano de 2010 que apresentou temperatura média anual de $25,7^{\circ} \mathrm{C}$ e acumulado anual de $1.386,9 \mathrm{~mm}$, enquanto os anos imediatamente anterior e posterior (2009 e 2011) apresentaram 1.197,1 mm e 961,6 mm, respectivamente. Segundo Passos et al (2012), esse comportamento pode ser justificado através da atuação da ASAS, a qual tem relação direta com o El Niño, visto que os ventos associados a ASAS sofrem intensificação em períodos de El Niño. E, segundo Degola (2013), a posição do ASAS varia conforme a incidência de radiação, a qual influencia na temperatura.

A figura 6 traz uma comparação entre os dados de temperatura média mensal da série histórica de 2008-2018 com os dados apresentados nas normais climatológicas. Ao longo do tempo, observa-se que a temperatura média do município de São Gonçalo-RJ apresenta um aumento positivo quando comparado às normais climatológicas, sendo observado em janeiro 29, $4^{\circ} \mathrm{C}$ na Estação Climatológica Experimental Urbana de São Gonçalo-RJ, enquanto nos 
dados do INMET são mostrados $26,2^{\circ} \mathrm{C}$, ou seja, os dados de São Gonçalo-RJ estão $3,2^{\circ} \mathrm{C}$ acima da média no mês em questão. Em fevereiro e outubro esse aumento é um pouco maior, com $3,6^{\circ} \mathrm{C}$, e em dezembro o aumento é de $3,7^{\circ} \mathrm{C}$ acima da média do INMET. Em contrapartida, no período seco percebe-se que não há aumento significativo, visto que o maior aumento observado foi no mês de julho, com $1,1^{\circ} \mathrm{C}$ acima da média do INMET. No primeiro mês do período seco, maio apresenta a menor elevação de toda a série histórica, com apenas $0,9^{\circ} \mathrm{C}$ acima das normais climatológicas.

Figura 6 - Comparação da temperatura média mensal.

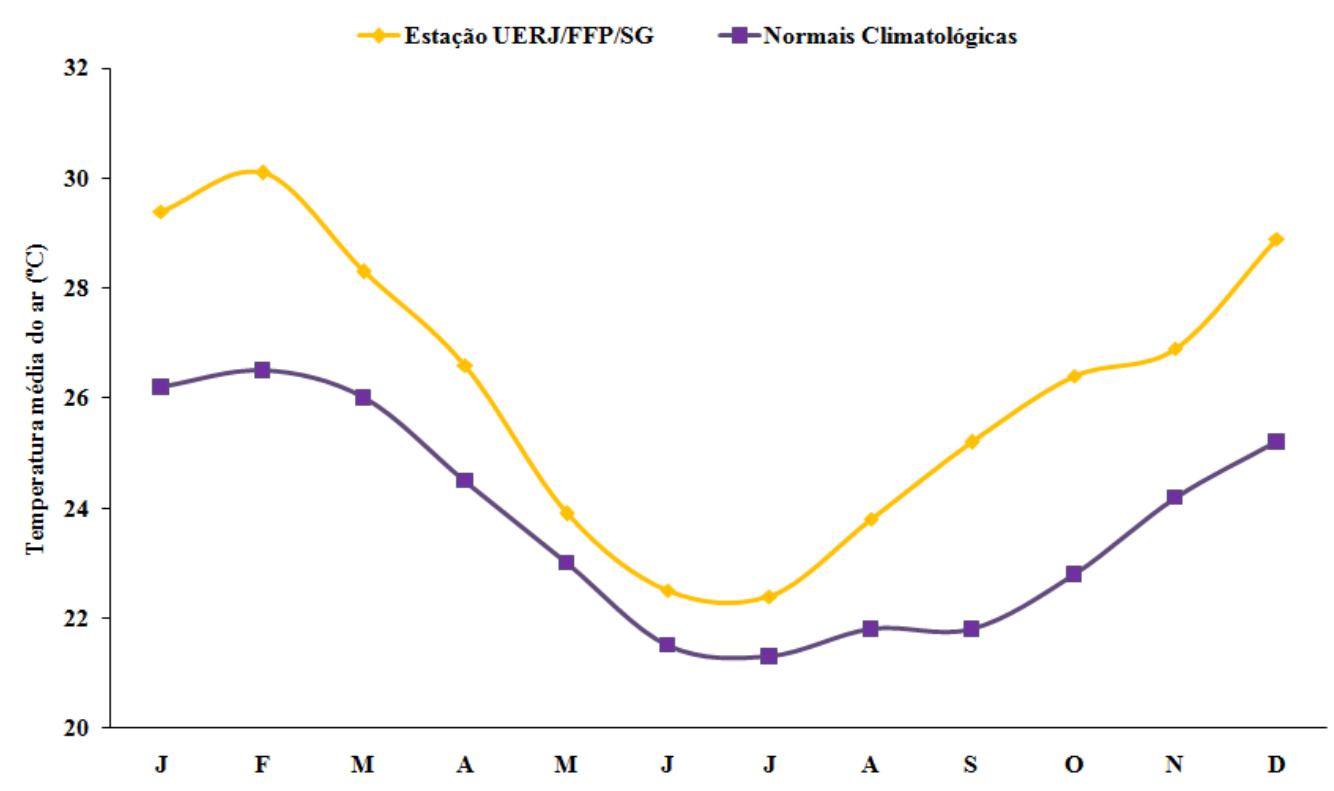

Fonte: Laboratório de Geociências da UERJ/FFP.

\section{Evaporação e Precipitação}

A maior diferença de percentual entre a precipitação e evaporação pode ser observada mais claramente nos meses de fevereiro, agosto e setembro, visto que no mês de fevereiro, os dados de evaporação alcançaram 188,6 mm, enquanto os dados de chuva apenas $78,7 \mathrm{~mm}$, mostrando uma diferença de 58\% (figura 7). No mês de agosto, tem-se 119,2 mm de evaporação e $23,6 \mathrm{~mm}$ de chuva, com percentual de $80 \%$, no mês de setembro $117,7 \mathrm{~mm}$ de água evaporada, enquanto $38,2 \mathrm{~mm}$ de precipitação, apresentando uma diferença de $67 \%$. No geral, os dados de chuva apresentam uma curva com um declínio bastante expressivo entre os meses de maio (40,4 $\mathrm{mm}$ ) e setembro $(38,2 \mathrm{~mm})$, os quais configuram a estação seca. Em contrapartida, pode-se observar que a curva de evaporação se apresenta bastante homogênea quando comparada à de precipitação, apresentando pequenas variações ao longo do ano. 
Figura 7 - Médias mensais de evaporação e precipitação.

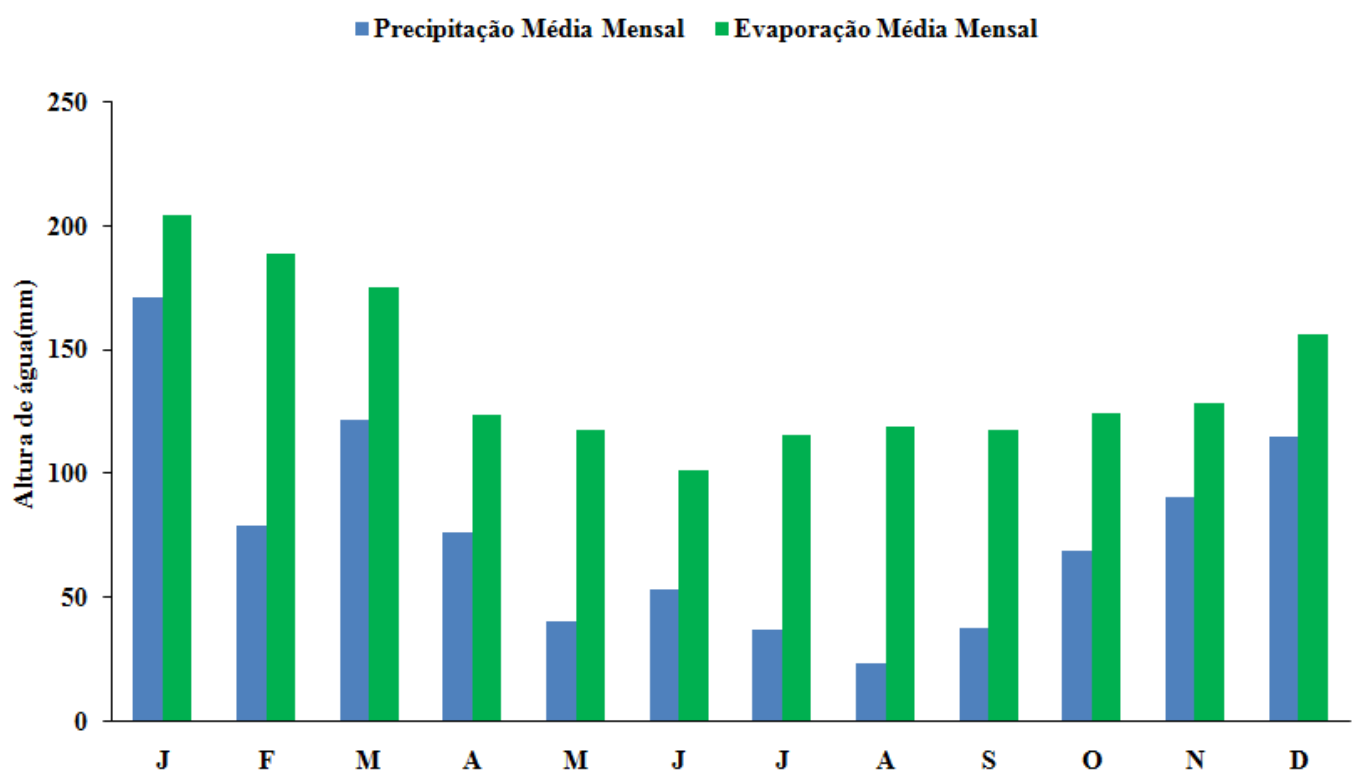

Fonte: Laboratório de Geociências da UERJ/FFP.

\section{Relação entre Evaporação, Umidade Relativa e Velocidade do Vento}

Percebe-se que o mês de janeiro apresentou a maior taxa de evaporação com 203,8 $\mathrm{mm}$, e umidade relativa média de $55 \%$. Enquanto, o mês de junho apresentou a menor média com 101,2 mm de evaporação e $64 \%$ de umidade relativa média. No período seco houve maior umidade relativa média sendo a maior $64 \%$, enquanto no período úmido a maior média alcançou $61 \%$. Esse comportamento pode ser justificado de acordo com a análise das estações do ano em que a umidade relativa cresce conforme a temperatura diminui (VAREJÃO-SILVA, 2006), portanto, os meses que possuem as maiores umidades relativas médias vão de maio a setembro, meses próximos e/ou dentro do inverno, onde as temperaturas são mais baixas. Existe ainda a confirmação da relação entre a evaporação e a velocidade do vento que, segundo Varejão-Silva (2006, p. 393), consiste na afirmativa de que o "fluxo de vapor d'água vertical para a atmosfera está condicionado pelo saldo de energia disponível, pela velocidade do vento [...]", entre outros fatores. Os meses de janeiro, fevereiro e março apresentaram registros de maior velocidade do vento e, consequentemente, maior taxa de evaporação. E nos meses entre abril e novembro a evaporação diminui de 155,9 mm (registrado em dezembro) para 101,2 mm, registrado no mês de junho. 
Entre os meses de maio e julho, a temperatura média começou a apresentar redução, em contrapartida, a umidade relativa se elevou, implicando na diminuição da taxa de evaporação, ainda que a velocidade do vento não tenha se alterado, devido à chegada do inverno. Já entre os meses de agosto e novembro registrou-se um aumento na velocidade do vento $12,3 \mathrm{~km} / \mathrm{h}$ e $13,8 \mathrm{~km} / \mathrm{h}$, respectivamente, devido à chegada da primavera (LOPES et al, 2000), o que normalmente implica na taxa de evaporação. Entretanto, a mesma sofreu influência da umidade relativa do ar, que se apresentou em torno de $60 \%$ ao longo dos meses destacados.

Tabela 4 - Médias mensais registradas na UERJ/FFP/SG.

\begin{tabular}{c|c|c|c}
\hline Meses & $\begin{array}{c}\text { Evaporação } \\
(\mathbf{m m})\end{array}$ & $\begin{array}{c}\text { Umidade } \\
\text { Relativa }(\%)\end{array}$ & $\begin{array}{c}\text { Velocidade do } \\
\text { Vento }(\mathbf{k m} / \mathbf{h})\end{array}$ \\
\hline Janeiro & 203,8 & 55 & 9,3 \\
\hline Fevereiro & 188,6 & 53 & 11,0 \\
\hline Março & 174,9 & 56 & 9,5 \\
\hline Abril & 123,8 & 57 & 7,4 \\
\hline Maio & 117,3 & 64 & 7,4 \\
\hline Junho & 101,2 & 64 & 7,3 \\
\hline Julho & 115,4 & 64 & 8,7 \\
\hline Agosto & 119,2 & 59 & 12,3 \\
\hline Setembro & 117,7 & 60 & 13,6 \\
\hline Outubro & 124,4 & 60 & 15,2 \\
\hline Novembro & 128,4 & 61 & 13,8 \\
\hline Dezembro & 155,9 & 61 & 11,9 \\
\hline
\end{tabular}

Fonte: Laboratório de Geociências da UERJ/FFP.

Segundo as relações entre a evaporação, a velocidade do vento e a umidade relativa do ar apresentadas por Varejão-Silva, (2006), observa-se que, ainda que a velocidade do vento tenha se elevado, a taxa de evaporação reduziu devido à temperatura. Além dos dados de temperaturas média e extremas, acumulados de precipitação e as taxas de evaporação, foram analisados também a relação entre a insolação total e a nebulosidade média anual.

\section{Insolação}

De acordo com a análise da figura 8 há uma grande proximidade dos dados registrados na Estação Climatológica Experimental Urbana com os dados obtidos das normais climatológicas entre os meses de maio a setembro e dezembro, referente à insolação total. No mês de janeiro se observa uma redução de 56,9 décimos de horas em relação às normais do INMET. 
O mês de novembro também apresenta um valor inferior, porém de 39,6 décimos de horas de insolação a menos em relação às normais climatológicas. Isso pode indicar que, em relação às nuvens, ainda que a cobertura tenha sido menor em relação às normais do INMET, as mesmas possuíam um desenvolvimento vertical superior, devido à quantidade de chuva registrada nos meses em questão. Como exemplo, podemos citar o mês de janeiro onde choveu 170,8 mm, com 56,7 mm acima da média esperada. Já novembro apresentou um valor de insolação menor que o esperado, de onde se pode concluir que ao longo do período não houve nuvens com significativa atividade convectiva, registrando $90,3 \mathrm{~mm}$ de chuva, apenas $5,3 \mathrm{~mm}$ abaixo da média esperada para o mês.

No mês de agosto, os dados de insolação tanto registrados na estação UERJ/FFP/SG quanto das Normais Climatológicas foram exatamente iguais, com 178,05 décimos de horas. Esta diferença pode ser explicada pela localização geográfica do município de São Gonçalo-RJ no recôncavo da Baía de Guanabara, que registra menores acumulados de chuva com relação ao município do Rio de Janeiro por seu sítio (FIALHO, 2012) de fundo de baía, além de existir nessa área o efeito de sombra de chuva devido aos maciços costeiros. Tal efeito consiste em reter a umidade a barlavento, reduzindo a umidade e o acumulado de chuva.

Figura 8 - Insolação total registrada na UERJ/FFP x Normais Climatológicas na Estação SBRJ.

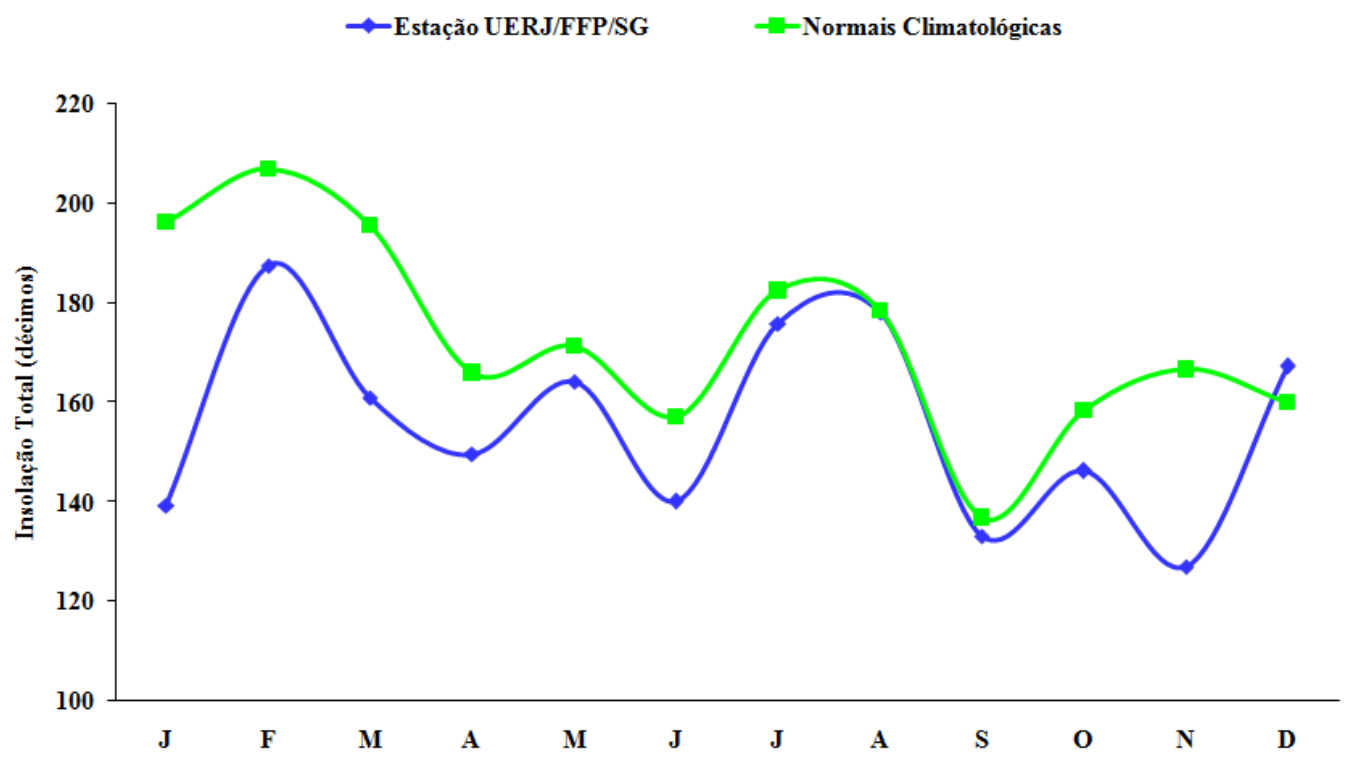

Fonte: Laboratório de Geociências da UERJ/FFP. 


\section{Relação entre Nebulosidade e Insolação}

De acordo com a análise de toda a série histórica mostrada na Figura 9, pode-se perceber que ao longo do ano, há uma homogeneidade na cobertura de nebulosidade, variando de 4 a 6 décimos, sendo 4 décimos nos meses de fevereiro, julho e agosto; além de 6 décimos nos meses de outubro e novembro. Os meses de fevereiro, julho e agosto apresentam maior quantidade de insolação, sendo o dado mais significativo em fevereiro com 187,6 décimos de hora, seguido por agosto com 178,1 décimos de horas e por último, o mês de julho com 175,9 décimos de hora.

Os meses que apresentam maior quantidade de nebulosidade, em contrapartida, registraram menores quantidades de horas de sol descoberto, como nos meses de outubro e novembro, sendo o último com insolação de 127,1 décimos de horas, a qual também equivale à menor de todas as médias, seguido de outubro com 146,3 décimos de horas.

Figura 9 - Dados de nebulosidade média x Insolação total, registrados em UERJ/FFP/SG x Normais Climatológicas na Estação SBRJ.

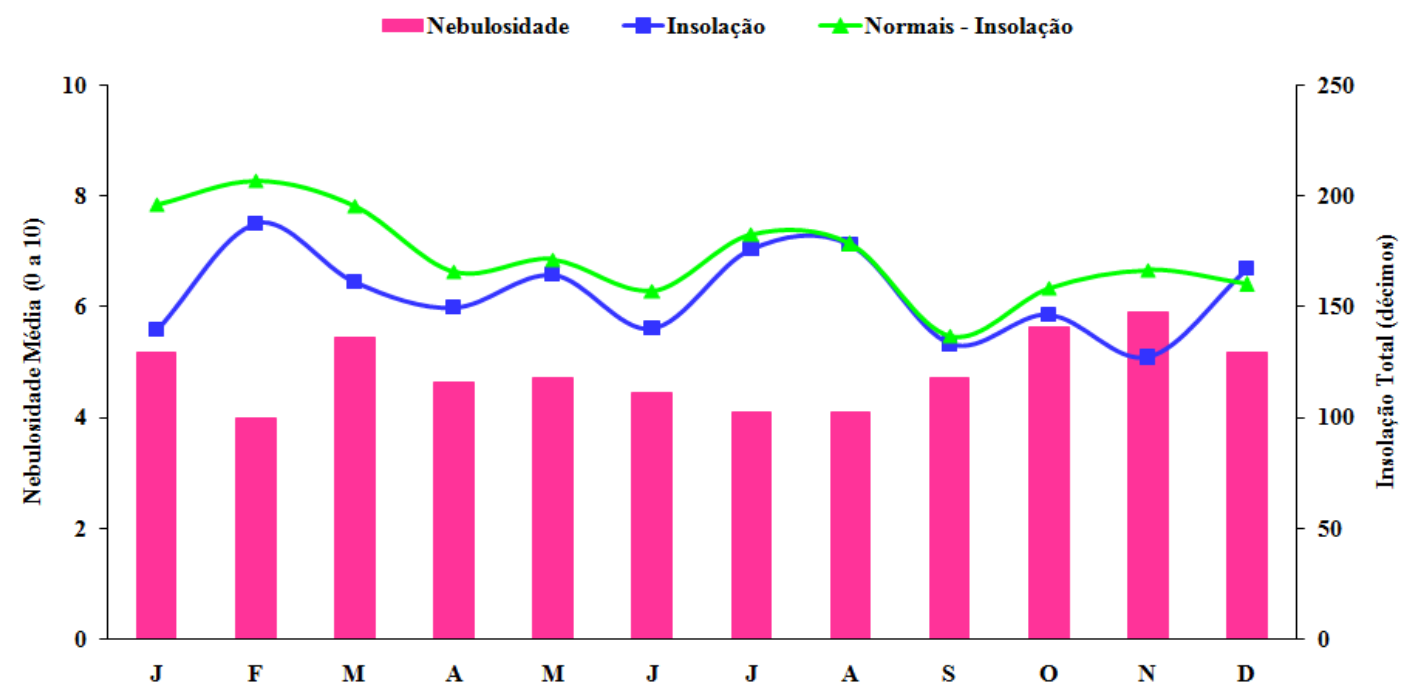

Fonte: Laboratório de Geociências da UERJ/FFP.

\section{Relação entre a Pressão Atmosférica e a Velocidade do Vento}

$\mathrm{Na}$ tabela 5 a pressão atmosférica apresenta um comportamento que pode ser explicado devido ao sistema semipermanente da ASAS de característica seca e quente. Este sistema se localiza nas proximidades das latitudes de $30^{\circ}$ em regiões oceânicas, onde gera subsidência de ar, inibindo a formação de nebulosidade e sofrem alteração de sua posição relacionada à intensa radiação solar tropical, altas temperaturas e elevada umidade específica 
sobre o oceano (DEGOLA, 2013; NIMER, 1979) que varia conforme se caminha para o verão, quando devido a seu posicionamento passa a soprar ventos úmidos, formando nuvens e deixando a pressão mais baixa (PEREIRA et al., 2019). Tais influências podem ser notadas nos meses de inverno, sendo destacado o mês de julho, com $1.022 \mathrm{hPa}$, enquanto no verão a pressão baixou a $1.012 \mathrm{hPa}$ no mês de março (BASTOS; FERREIRA, 2000).

Os dados de vento podem ser explicados devido ao comportamento dos sistemas atuantes na localidade. No inverno, ainda que existam outros fenômenos atuantes, a ASAS predomina por estar localizada no interior do continente. Dessa forma, a mesma ocasiona dificuldade na aproximação de sistemas frontais, gerando gradiente de pressão pouco expressivo. Devido a essa redução dos gradientes de pressão, a velocidade do vento se reduz, justificando as velocidades de $7,3 \mathrm{~km} / \mathrm{h}$ no mês de junho, sendo a menor média de velocidade registrada em todos os meses do ano.

Já entre os meses de setembro e novembro, período de primavera, é possível perceber o aumento da velocidade média do vento em quase o dobro do observado no período do inverno, sendo outubro o mês que apresentou maior valor, com 15,2 km/h. Esta variação pode ser explicada devido à primavera ser uma estação de transição entre o inverno e o verão, marcada por instabilidade atmosférica, permitindo que os sistemas frontais consigam entrar e atuar com maior frequência na área (CPTEC - INPE, 2016).

Tabela 5 - Velocidade do vento x pressão atmosférica registrados em UERJ/FFP/SG.

\begin{tabular}{c|c|c}
\hline Meses & $\begin{array}{c}\text { Velocidade do } \\
\text { Vento }(\mathbf{k m} / \mathbf{h})\end{array}$ & $\begin{array}{c}\text { Pressão } \\
\text { Atmosférica } \\
\mathbf{( h P a})\end{array}$ \\
\hline Janeiro & 9,3 & 1.014 \\
\hline Fevereiro & 11,0 & 1.015 \\
\hline Março & 9,5 & 1.012 \\
\hline Abril & 7,4 & 1.017 \\
\hline Maio & 7,4 & 1.019 \\
\hline Junho & 7,3 & 1.022 \\
\hline Julho & 8,7 & 1.022 \\
\hline Agosto & 12,3 & 1.022 \\
\hline Setembro & 13,6 & 1.020 \\
\hline Outubro & 15,2 & 1.017 \\
\hline Novembro & 13,8 & 1.015 \\
\hline Dezembro & 11,9 & 1.014 \\
\hline Fonte: Laborati
\end{tabular}

Fonte: Laboratório de Geociências da UERJ/FFP. 


\section{Temperaturas do Solo}

Analisando as temperaturas do solo, de acordo com a tabela 6, as temperaturas em 11 $\mathrm{cm}$ seguem se alterando conforme as estações do ano, sendo as mais elevadas no período úmido devido à maior quantidade de radiação incidente no solo, apresentando seu ápice no mês de fevereiro com $30,4^{\circ} \mathrm{C}$ e a mínima em julho com $22,2^{\circ} \mathrm{C}$. No nível de $21 \mathrm{~cm}$ de profundidade mostram dados de temperatura bastante próximos, sendo a diferença de, no máximo, $0,5^{\circ} \mathrm{C}$ no mês de junho. Na profundidade de $31 \mathrm{~cm}$, é possível perceber maior diferença entre as temperaturas quando comparadas às de $21 \mathrm{~cm}$ e, principalmente, às de 11 $\mathrm{cm}$ de profundidade. Isso ocorre devido ao fluxo de calor no solo. A radiação solar incidente é retransmitida pelas camadas inferiores do solo e outra parte é transmitida para a atmosfera (SENTELHAS et al., 2012).

No mês de janeiro, percebe-se aproximadamente $1^{\circ} \mathrm{C}$ de diferença quando a temperatura em $31 \mathrm{~cm}$ de profundidade é comparada à temperatura em $21 \mathrm{~cm}$, sendo a maior alteração do período úmido. $\mathrm{E} 1,2^{\circ} \mathrm{C}$ quando comparado à temperatura em $11 \mathrm{~cm}$ de profundidade, sendo também a maior diferença no período úmido. A menor diferença de todos os meses foi em abril, quando ocorreu uma exceção, ficando a temperatura em $31 \mathrm{~cm}$ menor do que em $21 \mathrm{~cm}$, reduzindo em $0,03^{\circ} \mathrm{C}$.

A menor diferença entre a temperatura em $31 \mathrm{~cm}$ e a temperatura em $11 \mathrm{~cm}$ ocorreu no mês de dezembro com $0,7^{\circ} \mathrm{C}$, mostrando que o mês teve bastante radiação incidente. No período seco, o mês em que a temperatura em $31 \mathrm{~cm}$ apresentou maior alteração foi em maio com $0,9^{\circ} \mathrm{C}$ aproximadamente em relação à temperatura em $21 \mathrm{~cm}$. Quanto à temperatura em $11 \mathrm{~cm}$, o mês que apresentou maior discrepância no período seco foi o mês de junho.

Tabela 6 - Médias mensais de temperatura do solo registradas na UERJ/FFP/SG.

\begin{tabular}{c|c|c|c}
\hline Meses do ano & $\begin{array}{c}\mathbf{1 1} \mathbf{~ c m ~ d e} \\
\text { profundidade }\left({ }^{\mathbf{}}{ }^{\circ} \mathbf{C}\right)\end{array}$ & $\begin{array}{c}\mathbf{2 1 ~ c m ~ d e} \\
\text { profundidade }\left({ }^{\mathbf{o}} \mathbf{C}\right)\end{array}$ & $\begin{array}{c}\mathbf{3 1} \mathbf{~ c m ~ d e} \\
\text { profundidade }\left({ }^{\circ} \mathbf{C}\right)\end{array}$ \\
\hline Janeiro & 29,9 & 30,1 & 31,1 \\
\hline Fevereiro & 30,4 & 30,5 & 31,2 \\
\hline Março & 29,2 & 29,5 & 30,3 \\
\hline Abril & 27,3 & 28,4 & 28,4 \\
\hline Maio & 24,6 & 24,9 & 25,8 \\
\hline Junho & 22,7 & 23,2 & 24,1 \\
\hline Julho & 22,2 & 22,5 & 23,6 \\
\hline Agosto & 22,9 & 23,2 & 24,1 \\
\hline Setembro & 24,4 & 24,8 & 25,6 \\
\hline Outubro & 26,1 & 26,5 & 27,1 \\
\hline Novembro & 27,2 & 27,6 & 28,4 \\
\hline Dezembro & 28,9 & 29,1 & 29,6 \\
\hline
\end{tabular}


Fonte: Laboratório de Geociências da UERJ/FFP.

Observando a tabela 6, é possível perceber que em todos os meses do ano, a temperatura em $31 \mathrm{~cm}$ de profundidade segue sendo superior às demais, porém, ambas acompanham um perfil semelhante, alcançando os $30^{\circ} \mathrm{C}$ em janeiro e ultrapassando-o em fevereiro e reduzindo à aproximadamente $22^{\circ} \mathrm{C}$ no ápice do período seco, no mês de julho. Isso ocorre devido à posição da Terra em relação ao Sol, pois no período entre os finais de março e de setembro o hemisfério Sul recebe menos energia solar, justificando a queda de temperatura do solo nos meses em questão (VAREJÃO-SILVA, 2006).

Os dados de geotemperaturas em declínio podem ser equiparados com os dados de insolação na figura 8 , visto que a partir do mês de março a insolação diminui e segue menor até o mês de setembro, confirmando o motivo da queda da geotemperatura.

\section{CONSIDERAÇÕES FINAIS}

Os dados de precipitação nos anos de 2010, 2008 e 2009 demonstraram que foram os anos que registraram os maiores acumulados de chuva em seus períodos úmidos, estando esse comportamento associado aos centros de baixa pressão que atuavam no litoral fluminense. Isso resultou em problemas diversos para a população.

É importante salientar que o estudo de caracterização climática deve ser considerado como ferramenta para o planejamento territorial e ambiental do município, pois pode auxiliar na minimização de problemas relacionados a perdas de bens, transtornos sociais e econômicos e problemas ambientais. Entender as características meteorológicas de uma área pode auxiliar no melhor entendimento das inundações e movimentos de massa. Além disso, o aumento da urbanização sem planejamento resulta em maior vulnerabilidade da população em relação a esses eventos.

A partir desse trabalho que se estendeu dos anos de 2008 a 2018, verificou-se que o município de São Gonçalo continua com a tendência de clima Aw, o qual é denominado Clima Tropical Úmido, sendo bastante caracterizado pelas chuvas de verão e outono, permitindo confirmar, através de maior série histórica, o que foi mostrado em trabalhos anteriores.

\section{AGRADECIMENTOS}

Os autores agradecem ao Programa de Apoio Técnico às atividades de ensino, pesquisa e extensão (PROATEC/SR-2 - UERJ). 


\section{REFERÊNCIAS}

ALHO, D. S.; TORNIO, C. A. A.; KEDE, M. L. F. M. O ensino de climatologia para estudantes de $6^{\circ}$ ano do ensino fundamental. In: SIMPÓSIO BRASILEIRO DE GEOGRAFIA FÍSICA APLICADA, 18., 2019. Ceará. Anais do... Fortaleza: UFC, 2019. Disponível em: http://www.editora.ufc.br/images/imagens/pdf/geografia-fisica-e-as-mudancas-globais/229.pdf. Acesso em: 23 mar. 2020.

AMADOR, E. S. Baía da Guanabara e Ecossistemas Periféricos: Homem e Natureza. Rio de Janeiro. Edição do Autor, 1997. $539 \mathrm{p}$.

AYOADE, J. O. Classificações climáticas e climas regionais. In: AYOADE, J. O. Introdução à climatologia para os trópicos. 4. ed. Rio de Janeiro: Bertrand Brasil, 1996, p 231-234. Cap. 11. Tradução de Maria Juraci Zani dos Santos. Revisão de Suely Bastos. Coordenação editorial de Antonio Christofoletti.

BASTOS, C. C.; FERREIRA, N. J. Análise Climatológica da Alta Subtropical do Atlântico Sul. In: CONGRESSO BRASILEIRO DE METEOROLOGIA, 11., 2000, Rio de Janeiro. Anais do... Rio de Janeiro, 2000. Disponível em: http://mtc-m16b.sid.inpe.br/col/sid.inpe.br/iris@1915/2005/03.15.19.20/doc/Bastos_Analise\%20climatologica.pdf. Acesso em: 12 jun. 2020.

BERTOLINO, A. V. F. A. et al. Análise da dinâmica climatológica no município de São Gonçalo RJ - triênio 2004 - 2007. Revista Tamoios, São Gonçalo, v. 4, p. 1-13, 2007. Disponível em:

https://www.e-publicacoes.uerj.br/index.php/tamoios/article/view/624. Acesso em: 20 mar. 2020.

BERTOLINO, A. V. F. A. et al. As repercussões pluviais e os movimentos de massa na porção leste da Baía de Guanabara: estudo de caso de São Gonçalo - RJ. In: SILVA, C. A.; FIALHO, E. S. (org.). Concepções e Ensaios da Climatologia Geográfica. 1. ed. Dourados: UFGD, 2012. p. 233-256.

BERTOLINO, A. V. F. A. et al. Movimentos de massa no município de São Gonçalo. In: SANTOS, M. G. Biodiversidade e sociedade no Leste Metropolitano do Rio de Janeiro. Rio de Janeiro: Eduerj, 2016. p. 243-263.

BERTOLINO, L. C. et al. Análise dos deslizamentos em São Gonçalo - Rio de Janeiro: uma abordagem multi-escalar. Revista Geografias, Belo Horizonte, Edição Especial, n.3, p. 53-65, 2015. SEGEO.

BOGNOULS, F.; GAUSSEN, H. Estação seca e índice xerotérmico. Boletim Geográfico, Rio de Janeiro, v. 20, n. 169, 1962. Traduzido por Ruth Simões Bezerra dos Santos. Disponível em:

https://biblioteca.ibge.gov.br/visualizacao/periodicos/19/bg_1962_v20_n169_jul_ago.pdf. Acesso em: 23 mar. 2020.

BORSATO, V. A dinâmica climática do Brasil e massas de ares. Curitiba: Editora CRV, 2016. 184p.

BRANDÃO, A. M. P. M. As alterações climáticas na área metropolitana do Rio de Janeiro: uma provável influência do crescimento urbano. In: ABREU, M. (org.). Natureza e sociedade no Rio de Janeiro. Rio de Janeiro: Secretaria Municipal de Cultura, Turismo e Esporte, 1992. p. 143-200.

BRANDÃO, A. M. P. M.. O campo Térmico na Cidade do Rio de Janeiro. In: ENCUENTRO DE GEÓGRAFOS DE AMÉRICOS DE AMÉRICA LATINA, 6., 1997, Buenos Aires. Anais do... Buenos Aires, 1997. CD-ROOM.

BRANDÃO, A. M. P. M. O clima urbano da cidade do Rio de Janeiro. 1996. 362f. Tese (Doutorado em Geografia Física) - Faculdade de Filosofia, Letras e Ciências Humanas, Programa de Pós-Graduação em Geografia Física, Universidade de São Paulo, São Paulo, 1996.

BRANDÃO, A. M. P. M. Clima urbano e enchentes na cidade do Rio de Janeiro. In: GUERRA, A. J. T.; CUNHA, S. B. (org.). Impactos ambientais urbanos no Brasil. Rio de Janeiro: Ed. Bertrand Brasil, 2001. p. 47-109.

BRITO, T. T. et al. Multivariate analysis applied to monthly rainfall over Rio de Janeiro state, Brazil. Meteorology and Atmospheric Physics (Print), Berlin, v.1, p.1-10, 2016.

CARDOSO, A. P. et al. Fruticultura Tropical: Espécies Regionais Exóticas. 1. ed. [s. l.]: Embrapa, 2009. p. 476-509. Cap. 22. Disponível em: https://www.embrapa.br/busca-de-publicacoes/-/publicacao/657773/uva. Acesso em: 13 ago. 2020.

CARVAlHO, L. M. V.; JONES, C. Zona de Convergência do Atlântico Sul. In: CAVALCANTI, I. F. A. et al. (org.). Tempo e Clima no Brasil. São Paulo: Oficina de Textos, 2009. p. 95-109. 
CHADE, J. Calor no Sudeste subiu acima da média mundial em 2014. Revista Exame, 2015. Disponível em: https://exame.abril.com.br/ciencia/calor-no-sudeste-subiu-acima-da-media-mundial-em-2014/. Acesso em: 24 mar. 2020.

CORREAA, D. S. O clima urbano no município de São Gonçalo: uma análise episódica (28/07/04) da influência do complexo topográfico Patronato-Mineiro, no campo térmico do quarto distrito de São Gonçalo-Neves, em situação sazonal de inverno. 2005. 75p. Monografia (Licenciatura em geografia) - Faculdade de Formação de Professores, Universidade do Estado do Rio de Janeiro, São Gonçalo-RJ, 2005.

COSTA, F. H. L. Dinâmica hidrológica em bacia hidrográfica urbana: subsídios geomorfológicos ao entendimento das enchentes nas bacias dos rios Imboassu, Brandoas, Marimbondo, Pedrinhas e Pica-Pau. 2015. Monografia (Licenciatura em Geografia) - Faculdade de Formação de Professores, Universidade do Estado do Rio de Janeiro, São Gonçalo-RJ, 2015. Orientador Otávio Miguez Rocha Leão.

COSTA, A. C.; RODRIGUES, R. A.; PRADO, L. F. Distribuição geográfica das chuvas na malha urbana de Catalão (GO) em 2016-2017. In: MARTINS, F. P.; CURY, R. B. (org.). Geografia e meio ambiente. Ponta Grossa - PR: Atena, 2021. p. 146-159. Cap. 12.

CPTEC-CENTRO DE PREVISÃO DO TEMPO E ESTUDOS CLIMÁTICOS. 2016. Primavera. Disponível em: http://clima1.cptec.inpe.br/estacoes/\#c1. Acesso em: 13 de mai. 2019.

CPTEC-CENTRO DE PREVISÃO DO TEMPO E ESTUDOS CLIMÁTICOS. 2016. Mapas. Disponível em: http://agricultura.cptec.inpe.br/. Acesso em 27 de fev.2019.

DEGOLA, T. S. D. Impactos e Variabilidade do Anticiclone Subtropical do Atlântico Sul sobre o Brasil no Clima Presente e em Cenários Futuros. 2012. 112p. Dissertação (Mestrado em Geofísica e Ciências Atmosféricas) - Instituto de Astronomia, Universidade de São Paulo, São Paulo, 2013. Orientador: Tércio Ambrizzi.

DELAZERI, E. M. Análise pluviométrica e sua relação com as enchentes em São Gonçalo, uma análise espacial por georreferenciamento das ocorrências dos anos de 2006 a 2014. 2015. Monografia (Licenciatura em Geografia) Faculdade de Formação de Professores, Universidade do Estado do Rio de Janeiro, São Gonçalo-RJ, 2015. Orientadora: Ana Valéria Freire Allemão Bertolino.

EMBRAPA SOLOS. Sistemas de Produção: Tecnologias de Produção de Soja - Região Central do Brasil 2014. 1. ed. Londrina: Embrapa Soja, 2013. 265 p. Disponível em: https://ainfo.cnptia.embrapa.br/digital/bitstream/item/95489/1/SP-16-online.pdf. Acesso em: 13 ago. 2020.

FIALHO, E. S. Estudos Climáticos em Sítios Urbanos e Rurais. In: SILVA, C. A.; FIALHO E. S. (org.). Concepções e Ensaios da Climatologia Geográfica. Dourados-MS: Ed. UFGD, 2012. p. 83-112.

FIALHO, E. S. O clima urbano e sua contribuição ao planejamento da cidade por meio da elaboração de mapas climáticos. In: OSCAR JUNIOR, A. C.; BERAY, N. (org.). A climatologia geográfica no Rio de Janeiro: Reflexões, metodologias e técnicas para uma agenda de pesquisa. Curitiba: Editora Appris, 2018. p. 21-44.

FIALHO, E. S. Unidades climáticas urbanas: o caso da Ilha do Governador-RJ. Revista de Ciências Humanas, Viçosa-MG, v. 10, n. 1, p. 26-46, jan./jun. 2010. Disponível em: http://www.cch.ufv.br/revista/pdfs/artigo2vol10-1.pdf. Acesso em: 10 maio 2017

FIALHO, E. S.; BRANDÃO, A. M. P. M. Um estudo da pluviosidade nos anos padrões extremos da década de 1980 na metrópole carioca. In: SIMPÓSIO DE GEOGRAFIA FÍSICA APLICADA, 6, 1995, Goiânia. Anais do... Goiás: UFG, 1995. p. 68-71. Disponível em:

https://www.researchgate.net/publication/285236416_Um_estudo_da_pluviosidade_nos_anos_padroes_extremos_da_decada de 1980 na metropole carioca. Acesso em: 23 mar. $20 \overline{20}$.

FIALHO, E. S. et al. Os impactos pluviais em São Gonçalo. In: SIMPÓSIO BRASILEIRO DE GEOGRAFIA FÍSICA APLICADA, 11, 2005, São Paulo. Anais do... São Paulo: USP, 2005. CD-ROM.

FIALHO, E. S.; LELIS, J. J. L. Utilização do clima no planejamento como reflexo das condições ambientais nos centros urbanos. Revista Acta Geográfica, Boa Vista-RR, v. 1, n. 2, p. 29-41, 2007. Disponível em:

https://revista.ufrr.br/actageo/article/view/175/352. Acesso em: 10 mar. 2020. 
GONÇALVES, T. G. B. Periferias Segregadas, Segregação nas Periferias: por uma análise das desigualdades intraurbanas no município de São Gonçalo, RJ. 218p. 2012. Dissertação (Mestrado em Arquitetura e urbanismo) Faculdade de Arquitetura e Urbanismo, Universidade Federal do Rio de Janeiro. Rio de Janeiro, 2012. Orientadora Eliane da Silva Bessa.

IBGE - INSTITUTO BRASILEIRO DE GEOGRAFIA E ESTATÍSTICA. Cidades @ São Gonçalo-RJ. 2018. Disponível em: https://www.ibge.gov.br/cidades-e-estados/rj/sao-goncalo.html. Acesso em: 25 mar. 2020.

KEDE, M. L. F. M.; BERTOLINO, A. F. A.; BERTOLINO, L. C. Análise da precipitação sobre o efeito da Alta Subtropical do Atlântico Sul (ASAS) no município de São Gonçalo (RJ) no período de 2014 e 2015. In: SIMPÓSIO INTERNACIONAL DE CLIMATOLOGIA, 7., 2017, Petrópolis. Anais do... Petrópolis: SBMET, 2017.

LOPES, G. M. et al. Caracterização da velocidade e direção do vento em Mossoró-RN, para as quatro estações do ano. Mossoró/RN: ESAM, 2000. Disponível em:

https://docplayer.com.br/42644902-Caracterizacao-da-velocidade-e-direcao-do-vento-em-mossoro-rn-para-as-quatro-estacoes -do-ano.html. Acesso em: 14 mar. 2020.

MENDONÇA, D. S.; SOUZA, F. C. R. Inundações: uma análise na perspectiva climatológica e urbana. In: ENCONTRO NACIONAL DE GEÓGRAFOS, 16., 2010, Porto Alegre. Anais do... Porto Alegre: Associação de Geógrafos Brasileiros AGB, 2010. Tema: crise, práxis e autonomia: espaços de resistência e esperanças.

MERAT, G. S. et al. Avaliação físico-química em área de movimentos de massa no bairro porto da madama no município de São Gonçalo/RJ. In: SIMPÓSIO BRASILEIRO DE GEOGRAFIA FÍSICA APLICADA, 9., 2009, Viçosa. Anais do... Minas Gerais: UFV, 2009. Disponível em:

http://www.geomorfologia.ufv.br/simposio/simposio/trabalhos/trabalhos_completos/eixo11/036.pdf . Acesso em: 23 mar. 2020.

NOAA - NATIONAL OCEANIC AND ATMOSPHERIC ADMINISTRATION. NATIONAL WEATHER SERVICE. NATIONAL CENTERS FOR ENVIRONMENTAL PREDICTION. Cold \& Warm Episodes by Season. [online]. 2020. Disponível em: https://origin.cpc.ncep.noaa.gov/products/analysis_monitoring/ensostuff/ONI_v5.php. Acesso em: 23 mar. 2020.

NIMER, E. Climatologia do Brasil. Rio de Janeiro: IBGE, 1979.

OLIVEIRA, A. C. B. Dinâmica e espacialização dos movimentos de massa no município de São Gonçalo - RJ. 2015. Monografia (Graduação em licenciatura em Geografia) - Faculdade de Formação de Professores, Universidade do Estado do Rio de Janeiro. São Gonçalo-RJ, 2015. Orientação: Ana Valéria Freire Allemão Bertolino.

OLIVEIRA, A. G. A Importância dos dados das variáveis climáticas nas pesquisas em Geografia: um estudo de caso empregando a precipitação pluviométrica. Revista Caminhos de Geografia Uberlândia, v. 10, n. 32, p. 9-21, 2009. Disponível em: http://www.seer.ufu.br/index.php/caminhosdegeografia/article/view/15948/8998. Acesso: 16 mar. 2020.

OLIVEIRA JÚNIOR, J. F. et. al. Caracterização do Regime de Vento no Município de Seropédica, Rio de Janeiro (2001-2010). Floresta e Ambiente, Seropédica, v. 20, n. 4, p. 447-459, 2013.

PASSOS, E. N. et al. Análise do comportamento da circulação oceânica e atmosférica e ventos de El Niño e La Niña. In: CONGRESSO BRASILEIRO DE OCEANOGRAFIA, 5., 2012, Rio de Janeiro. Anais do... Rio de Janeiro, 2012. p. $2407-2413$

PEGORIM, J. ASAS ganha força sobre o Brasil. Climatempo [online], São Paulo, 2014. Disponível em: https://www.climatempo.com.br/noticia/asas-ganha-forca-sobre-o-brasil. Acesso em: 23 mar. 2020.

PEREIRA, G. C. Correlação dos dados de intensidade de chuva com as enchentes mais expressivas ocorridas no município de São Gonçalo - RJ no período de 2005 a 2008. 2009. Monografia (Licenciatura em Geografia) - Faculdade de Formação de Professores, Universidade do Estado do Rio de Janeiro, São Gonçalo, 2009.

PEREIRA, V. C. M. et al. Variabilidade Comportamental da Insolação e Nebulosidade em Anos sem e com El Niño (2012 e 2015). In: SIMPÓSIO BRASILEIRO DE GEOGRAFIA FÍSICA APLICADA, 18, 2019, Ceará. Anais do... Fortaleza: UFC, 2019. Disponível em: http://www.editora.ufc.br/images/imagens/pdf/geografia-fisica-e-as-mudancas-globais/513.pdf. Acesso em: 23 mar. 2020. 
PIMENTEL, L. C. G. et al. Caracterização do regime de vento em superfície na Região Metropolitana do Rio de Janeiro. Revista de Engenharia Sanitária e Ambiental, Rio de Janeiro, v. 19, n. 2, p. 121- 132, 2014.

PINGUELLI ROSA, L.; LACERDA, W. A. Tormentas Cariocas. Rio de Janeiro: COPPE-UFRJ, 1997. 162 p. ROSA, F. B. Análise pluviométrica e sua correlação com as ocorrências de movimentos de massa no bairro Engenho Pequeno - São Gonçalo/RJ: período de 2005 a 2011. 2013. Monografia (Licenciatura em Geografia) - Faculdade de Formação de Professores, Universidade Estadual do Rio de Janeiro, Rio de Janeiro, 2013.

ROSA, F. B. et al. Correlações entre pluviosidade e movimentos de massa no bairro do engenho pequeno - SG/RJ. In: WORKSHOP DE ENGENHARIA DE BIOSSISTEMAS, 4, 2018, Anais do... Niterói, 2018. Disponível em: https://www.researchgate.net/publication/339252572_CORRELACOES_ENTRE_PLUVIOSIDADE_E_MOVIMENTOS_D E_MASSA_NO_BAIRRO_DO_ENGENHO_PEQUENO_-SG_RJ. Acesso em: 21 mar. 2020.

RIBEIRO, E. R. F. et al. Mapeamento de inundação e ambiente urbano: uma análise baseada em geotecnologias e análise participativa. In: LOURENÇO, L.; NUNES, A. Riscos Hidrometeorológicos. Coimbra: Ed. Riscos, 2018. p. 181-198. Associação Portuguesa de Riscos, Prevenção e Segurança.

SALGADO, C. M. et al. Caracterização temporal e espacial da precipitação no entorno do Município de São Gonçalo (RJ) considerando a série histórica de 1968 a 2002. Sociedade \& Natureza (UFU. Impresso), v. 19, p. 19-31, 2007.

SANTOS, C. P. et al. Uso de leguminosas cudzu tropical e guandu no controle erosivo em argissolo vermelho distrófico abrupto no município de São Gonçalo/RJ. In: SIMPÓSIO DE CIÊNCIA DO SOLO, 3., 2019, Lavras. Anais do... Lavras, 2019. Tema: Sistemas de Produção, Tecnologia e Meio Ambiente.

SENTElHAS, P. C.; ANGELOCCI, L. R. Aula 6 - Temperatura do ar e do solo. 2012. São Paulo: [s. n.], 2012.30 Slides. Apresentação para a Escola Superior de Agricultura Luiz de Queiroz / USP. Disponível em:

http://www.esalq.usp.br/departamentos/leb/aulas/lce306/Aula6_2012.pdf. Acesso em: 10 mar. 2019.

SILVA. J. Relação entre dados pluviométricos e as ocorrências de movimentos de massa no município de São Gonçalo RJ nos anos de 2005 e 2006 e sua relevância para o planejamento em defesa e segurança civil. 2007. Monografia (Licenciatura em Geografia) - Faculdade de Formação de Professores, Universidade Estadual do Rio de Janeiro, São Gonçalo-RJ, 2007.

SILVA, J. A. Inventário de deslizamentos no município de São Gonçalo como subsídio ao mapeamento de áreas de risco. 2006. Monografia (Graduação em licenciatura em Geografia) - Faculdade de Formação de Professores, Universidade do Estado do Rio de Janeiro, São Gonçalo-RJ, 2006. Orientador Luiz Carlos Bertolino.

SILVA, L. F. H. S. et al. A Importância dos Estudos Climáticos no Município de São Gonçalo (RJ) e o Papel da Escola na Construção de uma Sociedade Consciente do Clima. In: SIMPOSIO INTERNACIONAL DE CLIMATOLOGIA, 8., 2019, Belém. Anais do... Belém, 2019. p. 740-752.

SISTEMA ALERTA RIO DA PREFEITURA DO RIO DE JANEIRO. Termos Meteorológicos [online]. Rio de Janeiro, 2020. Disponível em: http://www.sistema-alerta-rio.com.br/previsao-do-tempo/termosmet/. Acesso em: 17 ago. 2020.

SOUZA, G. C. A. et al. Avaliação do papel da urbanização e da precipitação na formação de enchentes no município de São Gonçalo (RJ). In: SIMPÓSIO DE GEOGRAFIA FÍSICA APLICADA, 11, 2005, São Paulo. Anais do... São Paulo: USP, 2005. p. 906-913.

TAVARES, A. C. Mudanças Climáticas. In: VITTE, A. C.; GUERRA, A. J. T. (org.). Reflexões sobre a Geografia Física no Brasil. Rio de Janeiro: Bertrand Brasil, 2004, p. 49-88.

TÓRNIO, C. A. A. Dinâmicas atmosféricas e a gênese das chuvas no município de São Gonçalo (RJ) no período de 2005 a 2016. 2019. 160p. Monografia (Licenciatura em Geografia) - Faculdade de Formação de Professores, Universidade do Estado do Rio de Janeiro, São Gonçalo-RJ, 2019.

TÓRNIO, C. A. A.; KEDE, M. L. F. M. Análise pluviométrica no município de São Gonçalo (RJ) no período de 2005 a 2016. In: PINHEIRO, L. S.; GORAYEB, A.(org.). Geografia física e as mudanças globais. Fortaleza: Editora UFC, 2019. E-book.

VAREJÃO-SILVA, M. A. Consequências meteorológicas dos movimentos da terra. In: VAREJÃO-SILVA, M. A. Meteorologia e Climatologia. Recife: [s. n.], 2006. p. 16-17. Versão digital 2. Disponível em: https://icat.ufal.br/laboratorio/clima/data/uploads/pdf/METEOROLOGIA_E_CLIMATOLOGIA_VD2_Mar_2006.pdf. Acesso em: 15 jul. 2018. 
VENDRAMINI, R. Neutralidade climática permanece no primeiro semestre de 2014 e mantém a variação das chuvas no Brasil. Jornal do Tempo [online], 2014. Disponível em:

http://jornaldotempo.uol.com.br/noticias.html/59464/neutralidade-climatica-permanece-no-primeiro-semestre-de-2014-e-man tem-a-variacao-das-chuvas-no-brasil/. Acesso em: 16 mar. 2020.

VIANELLO. R. L.; ALVES, A. R. Meteorologia básica e aplicações. Viçosa: Imprensa Universitária, 2012. 449 p.

WALTER, H. Vegetação e zonas climáticas. São Paulo: Editora Pedagógica e Universitária, 1986. 325 p.

\section{COMO CITAR ESTE TRABALHO}

Pereira, V. C; Bertolino, A.V. F.A; Kede, M. L. F. M; Corbo,A. R; Bertolino, L. C \& Fialho, E.S. Contribuições para a análise da dinâmica climatológica no município de São Gonçalo/RJ 2008-2018. Revista Tamoios, São Gonçalo, v. 17, n. 2, p. 111-136, 2021. Disponível em: https://doi.org/10.12957/tamoios.2021.58214. Acesso em: DD MM. AAAA. 